\title{
Temperature Trend Analysis in the North Pacific Watershed in Mexico
}

\author{
César Enrique Romero-Higareda, Luz Isela Peinado-Guevara, Samuel Campista-León, \\ Juana Cázarez-Martínez, Jorge Guillermo Sánchez-Zazueta, Rogelio Sánchez-Bañuelos \\ Unidad Académica Escuela de Biología, Universidad Autónoma de Sinaloa, Culiacán, México \\ Email: cesar romero 47@uas.edu.mx
}

Received 15 June 2014; revised 12 July 2014; accepted 5 August 2014

Copyright (C) 2014 by authors and Scientific Research Publishing Inc.

This work is licensed under the Creative Commons Attribution International License (CC BY).

http://creativecommons.org/licenses/by/4.0/

(c) (i) 0pen Access

\begin{abstract}
Through the monthly data of $\mathbf{7 1}$ meteorological stations of the North Pacific Watershed in northwest Mexico, the annual trends of nine temperature variables were estimated using the non-parametric Mann-Kendall test and the $Q$ Sen's slope estimator. Annual $Q$ Sen's slopes were analyzed in spatial terms using geographic variables as independent factors and likewise with Moran's $I$ index. Three major physiographic zones were used to perform a regional analysis using pooled data. The monthly trends were also analyzed. Divergent annual trends were found for the nine proposed variables and warming trends were predominant in almost all of them. Latitude is the most relevant factor in the spatial distribution of the $Q$ Sen's slopes. Four temperature variables were found statistically clustered, as depicted by the Moran's $I$ index. The largest regional $Q$ Sen's slopes values were found in the Coastal Plains. In this area a larger increase in minimum temperatures was observed, in contrast with the Sierra Madre regions, where the largest rate of increasing change was found in maximum temperatures. The monthly analysis indicates warming trends in the first six months of the year with a sudden decrease in July and also a noticeable decrease in the slope values in December.
\end{abstract}

\section{Keywords}

Climate Change, Northwest Mexico, Regional Analysis

\section{Introduction}

Inside the frame of climate change, mainly attributed to anthropogenic activities such as the emissions of green house gases and soil cover change [1], divergent temperature trends have been documented at different spatial and temporal scales. Evidence of the effects of human activities on climate systems have been described by modeling programs [2] [3] who predicted an increase in temperature associated to change in soil cover, essen- 
tially involving deforestation and the continuous emissions of greenhouse gases. Field evidence of these effects goes from local scales [4] [5] to a regional extent [6]-[8]. These processes have been described linked to transformation of natural forested areas into agriculture fields [9] [10], or due to larger climate processes [11]. Reference [12] gathered a substantial inventory of contemporary research of the evidence of land cover changes impact on climate and its effect at large distances. The potential effects of these human-induced changes are described by [13].

The divergent behavior of different temperature variables is also noticeable. [14] demonstrated that within the process of warming, there is a larger rate of increase of minimum temperatures in relation to maximum temperatures, decreasing the values of temperature range [15]. Similar results were reported at different time scales. Nevertheless [16], an inverse behavior was reported in the United States. These divergences could be associated to changes in the cloud cover [17] or changes in the soil cover [18].

For Mexico [19] the surface air temperature variability was specified. Also [20], the direction of minimum and maximum temperature trends as the components of temperature range were explored [21]. Illustrated opposing temperature trends in different spatio-temporal magnitude. In a regional context, increasing minimum trends were found in the Sonoran Desert [22]. [23] explains the divergent trends in temperature range in Zacatecas, Mexico for northwest Mexico and specifically for the area enclosed in the North Pacific Watershed analysis of temperature trends at this point have been relatively scarce. Climate is of paramount importance for biological responses and the distribution of living organisms [24] [25], and then is of primary relevance to explore the climate trends that affect them. Mean temperature is an important factor in plant responses [26] as well as extreme temperatures [27] [28]. This region is important in ecosystem terms given that most of this area is covered with relatively well-preserved different types of forests and that it also includes one of the most productive agricultural areas in Mexico.

\section{Materials and Method}

\subsection{The North Pacific Watershed}

The North Pacific Watershed is located in northwest Mexico (Figure 1). Its boundaries are delimited by the Comisión Nacional del Agua; this region include the entire state of Sinaloa, western Durango and Zacatecas, the southwestern corner of Chihuahua and northern Nayarit. The climate of this region is clearly seasonal and strongly influenced by the presence of the Sierra Madre Occidental that runs almost parallel to the Sea of Cortez, creating an orographic effect that catches a great portion of the incoming moisture from the Pacific Ocean in the windward slopes, this process cools warm and humid incoming air masses from the ocean and as it moves up into the mountains by the adiabatic effect it can create precipitation, mainly in the windward slopes. This effect is less evident if one moves latitudinally towards the north because among other factors, there is an increasing distance from the coast line to the Sierra Madre, this generates a wide array of climates along the coast to the upper slopes of the mountains. Minimum temperatures can reach below freezing points, especially in sites above 1000 meters above sea level henceforth masl and mainly in winter, below that altitude freezing temperatures are rare events, although temperatures below $10^{\circ} \mathrm{C}$ are frequent. Maximum temperatures commonly exceed $40^{\circ} \mathrm{C}$ in the summer; these events are more prevalent above $24^{\circ} \mathrm{N}$ and below 1000 masl. Annual average temperatures oscillate from $13^{\circ} \mathrm{C}$ in some sites in Durango and Chihuahua to $26^{\circ} \mathrm{C}-27^{\circ} \mathrm{C}$ in the coastal plains of Sinaloa. Temperature range established for this analysis as the difference between the maximum minus the minimum temperature vary in two ways: seasonally, when is more evident in winter due to the lack of moisture and 29 geographically, where the magnitude of the temperature range is less in southern and coastal site due to higher levels of humidity. The temperature behavior of this watershed is therefore determined in a coarse way by the complex interaction of altitude, latitude, longitude, and proximity to the sea and by the marked rainfall seasonality, creating an increasing aridity gradient from southeast to northwest and from higher grounds to the low plains.

\subsection{Physiographic Regions}

Three main physiographic regions conform the North Pacific Watershed; these are basically defined by altitude, which in turn is determined by the Sierra Madre Occidental, although in the southern edge it gets closer to the coast. The physiographic regions lie therefore parallel to the coastline and the Sierra Madre Occidental (Figure 2). The three regions here considered are: The Coastal Plains (CP) conformed by flat terrains with scattered low 


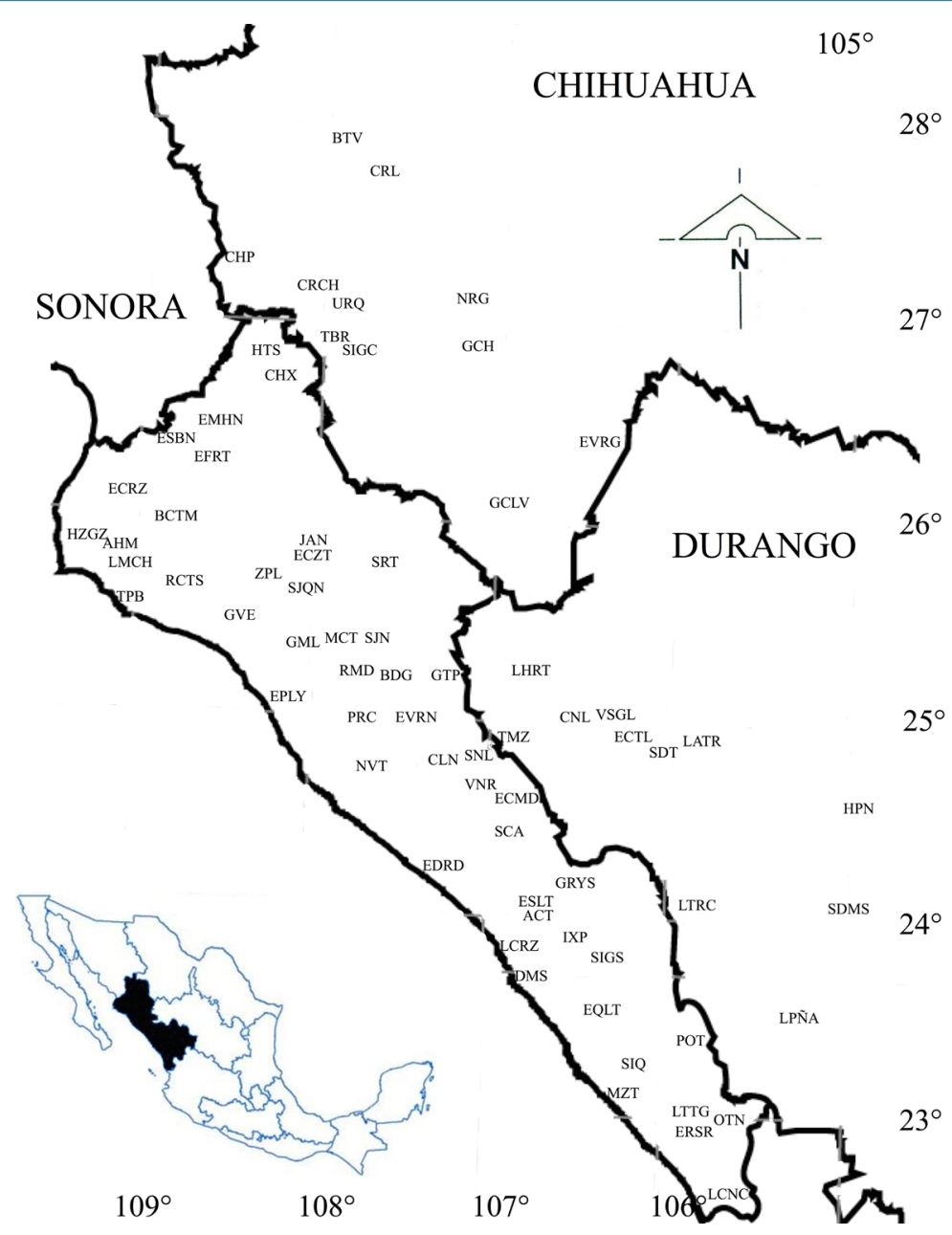

Figure 1. Selected stations of the North Pacific Watershed. Lower left inset: General extension of the North Pacific Watershed in Mexico. See text for abbreviations.

hills. Its width increases towards the northwest since the Sierra Madre lies farther from the coastline. Its altitude ranges from 0 to 100 - 150 masl. The Sierra Foothills (SF), which are composed basically from hills that increase gradually its altitude and steepness as one moves from west to east, its height ranges from 100 to 800 masl. Finally, the Sierra Madre region (SM) that inside averages $180 \mathrm{~km}$ from east to west. There is an increasing separation for this area from the coast, which goes from 50 - $60 \mathrm{~km}$ in the southern edge and reaches over 200 $\mathrm{km}$ in its northern limits. It is the most rugged region and its altitude exceeds 3000 masl in some points, but it averages 100 to 1700 masl. The main types of vegetation are described by [29], for the CP region the main types are mangroves along the coast lines and thorn forest or desert scrub; for the SF, the most conspicuous type of vegetation is the tropical dry forest, which is also the most extended form in the watershed, as one moves altitudinally towards the east, the vegetation changes to tropical sub-deciduous and oak forest. Finally in the SM region, the dominant forms are osk-pine and pine forest types of vegetation, this region also includes cloud forest.

\subsection{Climate Data and Variables}

For this study, we analyzed the data of 71 meteorological stations located in the windward slopes of the watershed, the stations were chosen on the basis of data integrity (Table 1). The first meteorological station in Sinaloa was installed in Mazatlán back in the XIX century, but a massive installation of new stations and homogenization of the measuring devices were done in the late 50s and early 60s, using the practical and theoretical 


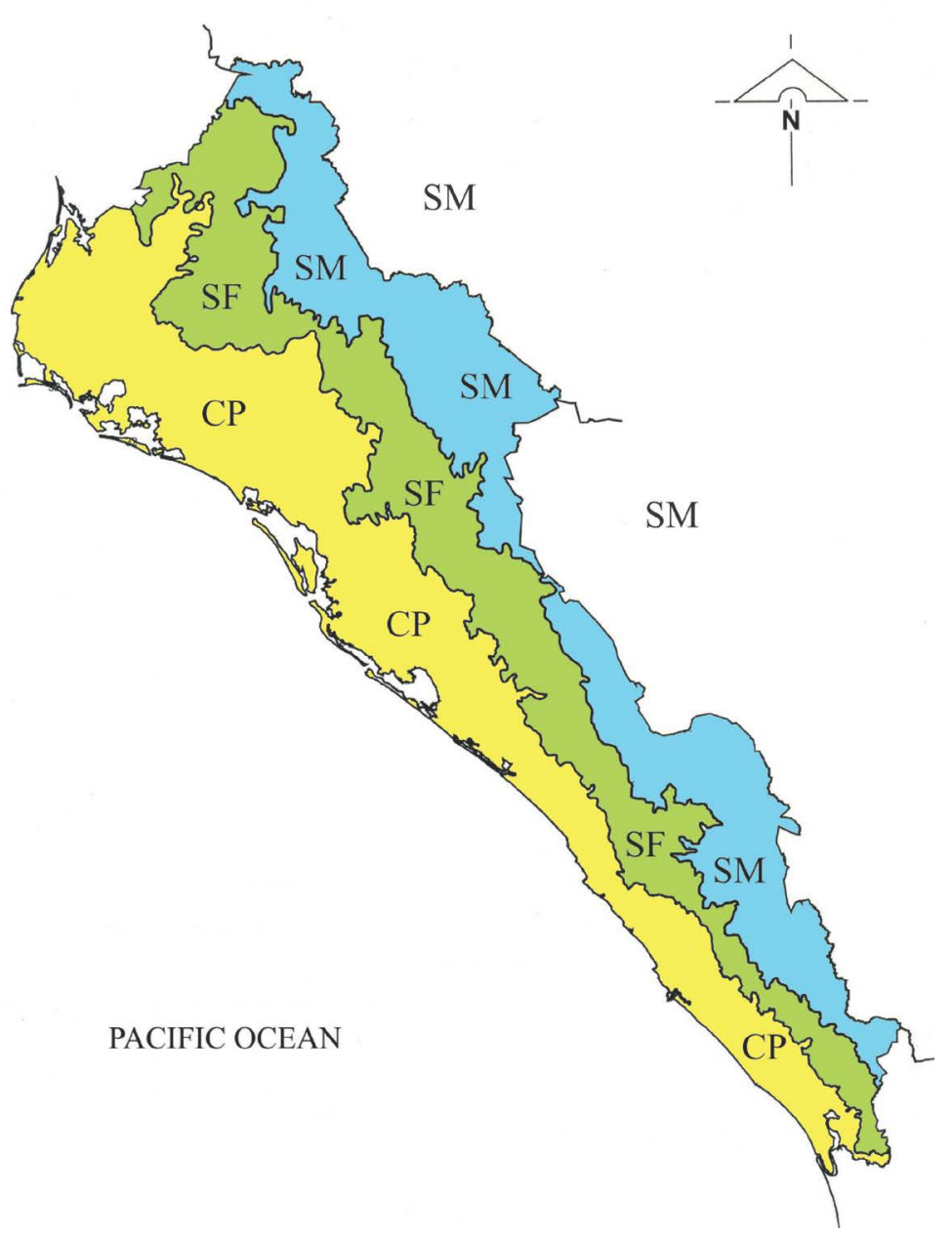

Figure 2. Physiographic regions of the North Pacific Watershed. CP stands for Coastal Plains (yellow), SF stands for Sierra Foothills (light green), SM stands for Sierra Madre (blue).

methods of the so-called in México American School. For mean temperatures, the measuring used device is a liquid-in-glass or common dry thermometer. For minimum temperatures, the Rutherford thermometer is used. For maximum temperatures the used device is a Negretti thermometer. The six type Rutherford thermometer can also be used for extreme minimum and maximum temperatures, based on availability [30]. With the exceptions of stations nearby or inside urban areas such as Los Mochis, Guamúchil, Guasave, Culiacán, Mazatlán and El Fuerte, the remaining stations are located outside urban areas, minimizing the heat-island effect [31]. The climate data consisted of monthly records of minimum, maximum and average temperatures. Minimum and maximum data were the extreme measurements of each month. In a first stage, we proposed nine temperature variables to build and analyze annual time series: 1) minimum temperature (TMin) which for each year was the lowest record; 2) minimum average temperature (TMinAvg), was calculated by averaging minimum records of each month for each year; 3) Mean temperature (TAvg) calculated by averaging all months mean temperatures; 4) maximum average temperature (TMaxAvg) calculated by averaging maximum monthly records for each year; 5) maximum temperature (TMax), that for each year it was the largest maximum measurement recorded in each year; 6) temperature range (TR), its annual value was estimated as the difference between the annual average maximum minus the annual minimum average temperature. We also considered the variability for minimum, average and maximum temperatures; these were estimated through the median absolute deviation since most of the monthly data for a particular year were not normally distributed, these variables were labeled as TMinMAD, TAvgMAD and TMaxMAD respectively (Table 2). We considered for minimum and maximum temperatures 
Table 1. Abbreviation, physiographic region, years of data and geographic position of selected meteorological stations of the North Pacific Watershed in Mexico.

\begin{tabular}{|c|c|c|c|c|c|c|}
\hline Site & Abbreviation & Region & Years of Data & Latitude N & Longitude W & Altitude (m) \\
\hline Acatitán & ACT & SF & $1962-2012$ & $24^{\circ} 05^{\prime} 49^{\prime \prime}$ & $-106^{\circ} 40^{\prime} 01^{\prime \prime}$ & 96 \\
\hline Ahome & AHM & $\mathrm{CP}$ & 1970-2009 & $25^{\circ} 55^{\prime} 08^{\prime \prime}$ & $-109^{\circ} 10^{\prime} 19^{\prime \prime}$ & 12 \\
\hline Boca Toma & ВСТМ & $\mathrm{CP}$ & $1962-2007$ & $26^{\circ} 04^{\prime} 14^{\prime \prime}$ & $-108^{\circ} 47^{\prime} 03^{\prime \prime}$ & 34 \\
\hline Badiraguato & BDG & SF & $1962-2012$ & $25^{\circ} 20^{\prime} 30^{\prime \prime}$ & $-107^{\circ} 32^{\prime} 35^{\prime \prime}$ & 189 \\
\hline Batovira & BTV & SM & $1975-2006$ & $27^{\circ} 55^{\prime} 05^{\prime \prime}$ & $-107^{\circ} 54^{\prime} 15^{\prime \prime}$ & 2153 \\
\hline Chinipas & CHP & SM & $1964-2012$ & $27^{\circ} 23^{\prime} 35^{\prime \prime}$ & $-108^{\circ} 32^{\prime} 09^{\prime \prime}$ & 435 \\
\hline Choix & CHX & SF & $1962-2012$ & $24^{\circ} 47^{\prime} 30^{\prime \prime}$ & $-107^{\circ} 23^{\prime} 53^{\prime \prime}$ & 239 \\
\hline Culiacán & CLN & $\mathrm{CP}$ & $1956-2012$ & $24^{\circ} 47^{\prime} 30^{\prime \prime}$ & $-107^{\circ} 23^{\prime} 53^{\prime \prime}$ & 60 \\
\hline Canelas & CNL & SM & $1960-2012$ & $25^{\circ} 06^{\prime} 00^{\prime \prime}$ & $-106^{\circ} 34^{\prime} 00^{\prime \prime}$ & 1754 \\
\hline Cerocahui & $\mathrm{CRCH}$ & SM & $1960-2006$ & $27^{\circ} 18^{\prime} 00^{\prime \prime}$ & $-108^{\circ} 03^{\prime} 00^{\prime \prime}$ & 1640 \\
\hline Creel & CRL & SM & 19682006 & $27^{\circ} 45^{\prime} 00^{\prime \prime}$ & $-107^{\circ} 38^{\prime} 15^{\prime \prime}$ & 2351 \\
\hline Dimas & DMS & $\mathrm{CP}$ & $1962-2012$ & $23^{\circ} 43^{\prime} 26^{\prime \prime}$ & $-106^{\circ} 46^{\prime} 54^{\prime \prime}$ & 19 \\
\hline El Comedero & ECMD & SF & $1980-2012$ & $24^{\circ} 37^{\prime} 05^{\prime \prime}$ & $-106^{\circ} 49^{\prime} 00^{\prime \prime}$ & 311 \\
\hline El Carrizo & ECRZ & $\mathrm{CP}$ & $1966-2006$ & $26^{\circ} 16^{\prime} 06^{\prime \prime}$ & -10902'14" & 9 \\
\hline El Cantil & ECTL & SM & $1959-2012$ & $24^{\circ} 54^{\prime} 40^{\prime \prime}$ & $-106^{\circ} 15^{\prime} 33^{\prime \prime}$ & 2248 \\
\hline El Cazanate & ECZT & SM & $1968-2005$ & $25^{\circ} 49^{\prime} 12^{\prime \prime}$ & $-108^{\circ} 01^{\prime} 12^{\prime \prime}$ & 848 \\
\hline El Dorado & EDRD & $\mathrm{CP}$ & $1993-2010$ & $24^{\circ} 19^{\prime} 25^{\prime \prime}$ & $-107^{\circ} 22^{\prime} 04^{\prime \prime}$ & 12 \\
\hline El Fuerte & EFRT & SF & $1959-2010$ & $26^{\circ} 24^{\prime} 59^{\prime \prime}$ & $-108^{\circ} 37^{\prime} 04^{\prime \prime}$ & 86 \\
\hline El Mahone & EMHN & SF & $1962-2005$ & $26^{\circ} 30^{\prime} 49^{\prime \prime}$ & $-108^{\circ} 35^{\prime} 49^{\prime \prime}$ & 144 \\
\hline El Playón & EPLY & $\mathrm{CP}$ & $1962-2012$ & $25^{\circ} 13^{\prime} 20^{\prime \prime}$ & $-108^{\circ} 11^{\prime} 25^{\prime \prime}$ & 6 \\
\hline El Quelite & EQLT & $\mathrm{CP}$ & $1979-2012$ & $23^{\circ} 33^{\prime} 26^{\prime \prime}$ & $-106^{\circ} 27^{\prime} 30^{\prime \prime}$ & 46 \\
\hline El Rosario & ERSR & $\mathrm{CP}$ & $1963-2012$ & $22^{\circ} 59^{\prime} 41^{\prime \prime}$ & $-105^{\circ} 51^{\prime} 41^{\prime \prime}$ & 32 \\
\hline El Sabino & ESBN & SF & $1966-2005$ & $26^{\circ} 29^{\prime} 31^{\prime \prime}$ & $-108^{\circ} 43^{\prime} 54^{\prime \prime}$ & 104 \\
\hline El Salto & ESLT & SF & $1998-2012$ & $24^{\circ} 07^{\prime} 15^{\prime \prime}$ & $-106^{\circ} 41^{\prime} 41^{\prime \prime}$ & 160 \\
\hline El Vergel & EVRG & SM & $1975-2005$ & $26^{\circ} 28^{\prime} 27^{\prime \prime}$ & $-106^{\circ} 23^{\prime} 17^{\prime \prime}$ & 2740 \\
\hline El Varejonal & EVRN & SF & $1962-2012$ & $25^{\circ} 05^{\prime} 40^{\prime \prime}$ & $-107^{\circ} 23^{\prime} 35^{\prime \prime}$ & 119 \\
\hline Guachochi & GCH & SM & $1980-2009$ & $26^{\circ} 49^{\prime} 09^{\prime \prime}$ & $-107^{\circ} 04^{\prime} 12^{\prime \prime}$ & 2398 \\
\hline Guadalupe y Calvo & GCLV & SM & $1959-2008$ & $26^{\circ} 06^{\prime} 00^{\prime \prime}$ & $-108^{\circ} 58^{\prime} 00^{\prime \prime}$ & 2352 \\
\hline Guamúchil & GML & $\mathrm{CP}$ & $1953-2012$ & $25^{\circ} 28^{\prime} 10^{\prime \prime}$ & $-108^{\circ} 05^{\prime} 30^{\prime \prime}$ & 44 \\
\hline Guadalupe y Reyes & GRYS & SM & $1997-2012$ & $24^{\circ} 16^{\prime} 08^{\prime \prime}$ & $-106^{\circ} 31^{\prime} 11^{\prime \prime}$ & 708 \\
\hline Guaténipa & GTP & SF & $1965-2012$ & $25^{\circ} 21^{\prime} 16^{\prime \prime}$ & $-107^{\circ} 13^{\prime} 01^{\prime \prime}$ & 252 \\
\hline Guasave & GVE & $\mathrm{CP}$ & $1969-2012$ & $25^{\circ} 33^{\prime} 45^{\prime \prime}$ & $-108^{\circ} 27^{\prime} 40^{\prime \prime}$ & 23 \\
\hline Huahuapan & HPN & SM & $1966-2012$ & $24^{\circ} 31^{\prime} 22^{\prime \prime}$ & $-105^{\circ} 57^{\prime} 06^{\prime \prime}$ & 1170 \\
\hline Huites & HTS & SF & $1962-2005$ & $26^{\circ} 53^{\prime} 34^{\prime \prime}$ & $-108 \mid 21 ' 15 "$ & 269 \\
\hline Higuera de Zaragoza & HZGZ & $\mathrm{CP}$ & $1962-2006$ & $25^{\circ} 58^{\prime} 12^{\prime \prime}$ & $-109^{\circ} 18^{\prime} 15^{\prime \prime}$ & 11 \\
\hline
\end{tabular}




\section{Conitnued}

\begin{tabular}{|c|c|c|c|c|c|c|}
\hline Ixpalino & IXP & SF & $1962-2012$ & $23^{\circ} 58^{\prime} 05^{\prime \prime}$ & $-106^{\circ} 36^{\prime} 30^{\prime \prime}$ & 95 \\
\hline Jaina & JAN & SF & $1962-2012$ & $25^{\circ} 53^{\prime} 9^{\prime \prime}$ & $-108^{\circ} 01^{\prime} 30^{\prime \prime}$ & 130 \\
\hline Los Altares & LALT & SM & $1973-2012$ & $24^{\circ} 59^{\prime} 20^{\prime \prime}$ & $-105^{\circ} 53 ' 30^{\prime \prime}$ & 2578 \\
\hline La Concha & LCNC & $\mathrm{CP}$ & $1960-2012$ & $22^{\circ} 31^{\prime} 45^{\prime \prime}$ & $-105^{\circ} 27^{\prime} 09^{\prime \prime}$ & 17 \\
\hline La Cruz & LCRZ & $\mathrm{CP}$ & $1993-2012$ & $23^{\circ} 54^{\prime} 50^{\prime \prime}$ & $-106^{\circ} 54^{\prime} 15^{\prime \prime}$ & 9 \\
\hline La Huerta & LHRT & SM & 1969-2012 & $25^{\circ} 21^{\prime} 47^{\prime \prime}$ & $-106^{\circ} 42^{\prime} 02^{\prime \prime}$ & 663 \\
\hline Los Mochis & $\mathrm{LMCH}$ & $\mathrm{CP}$ & $1959-2010$ & $25^{\circ} 48^{\prime} 03^{\prime \prime}$ & $-109^{\circ} 02^{\prime} 06^{\prime \prime}$ & 11 \\
\hline La Peña & LPÑA & SM & $1963-2012$ & $23^{\circ} 33^{\prime} 15^{\prime \prime}$ & $-105^{\circ} 24^{\prime} 39^{\prime \prime}$ & 2756 \\
\hline Las Truchas & LTRC & SM & $1962-2012$ & $24^{\circ} 10^{\prime} 28^{\prime \prime}$ & $-105^{\circ} 58^{\prime} 00^{\prime \prime}$ & 1291 \\
\hline Las Tortugas & LTTG & $\mathrm{SF}$ & $1979-2012$ & $23^{\circ} 05^{\prime} 44^{\prime \prime}$ & $-105^{\circ} 50^{\prime} 44^{\prime \prime}$ & 69 \\
\hline Mocorito & MCT & SF & $1965-2012$ & $25^{\circ} 28^{\prime} 58^{\prime \prime}$ & $-107^{\circ} 55^{\prime} 15^{\prime \prime}$ & 87 \\
\hline Mazatlán & MZT & $\mathrm{CP}$ & $1971-2012$ & $23^{\circ} 13^{\prime} 59^{\prime \prime}$ & $-106^{\circ} 25^{\prime} 39^{\prime \prime}$ & 4 \\
\hline Norogachi & NRG & SM & $1975-2005$ & $27^{\circ} 17^{\prime} 15^{\prime \prime}$ & $-107^{\circ} 07^{\prime} 32^{\prime \prime}$ & 2089 \\
\hline Navolato & NVT & $\mathrm{CP}$ & 1999-2012 & $24^{\circ} 45^{\prime} 56^{\prime \prime}$ & $-107^{\circ} 42^{\prime} 11^{\prime \prime}$ & 16 \\
\hline Otatitán & OTN & $\mathrm{SF}$ & 1980-2012 & $23^{\circ} 00^{\prime} 50^{\prime \prime}$ & $-105^{\circ} 40^{\prime} 00^{\prime \prime}$ & 96 \\
\hline Poterillos & POT & SM & $1968-2012$ & $23^{\circ} 27^{\prime} 13^{\prime \prime}$ & $-105^{\circ} 49^{\prime} 32^{\prime \prime}$ & 1571 \\
\hline Pericos & PRC & $\mathrm{CP}$ & $1962-2009$ & $25^{\circ} 05^{\prime} 35^{\prime \prime}$ & $-107^{\circ} 41^{\prime} 39^{\prime \prime}$ & 52 \\
\hline Ruiz Cortines & RCTS & $\mathrm{CP}$ & $1962-2006$ & $25^{\circ} 42^{\prime} 15^{\prime \prime}$ & $-108^{\circ} 43^{\prime} 09^{\prime \prime}$ & 19 \\
\hline Rosa Morada & RMRD & SF & $1962-2012$ & $25^{\circ} 22^{\prime} 00^{\prime \prime}$ & $-107^{\circ} 50^{\prime} 15^{\prime \prime}$ & 134 \\
\hline Santa Cruz Alayá & SCA & SF & $1962-2012$ & $24^{\circ} 29^{\prime} 15^{\prime \prime}$ & $-106^{\circ} 57^{\prime} 15^{\prime \prime}$ & 130 \\
\hline San Dimas & SDMS & SM & $1962-2012$ & $24^{\circ} 08^{\prime} 53^{\prime \prime}$ & $-105^{\circ} 57^{\prime} 10^{\prime \prime}$ & 904 \\
\hline San Diego Tenzaens & SDTZ & SM & 1973-2012 & $24^{\circ} 53^{\prime} 40^{\prime \prime}$ & $-106^{\circ} 07^{\prime} 15^{\prime \prime}$ & 1640 \\
\hline San Ignacio (Chihuahua) & SIGC & SF & $1965-2005$ & $26^{\circ} 59^{\prime \prime}$ & $-107^{\circ} 50^{\prime} 36^{\prime \prime}$ & 340 \\
\hline San Ignacio (Sinaloa) & SIGS & $\mathrm{SF}$ & $1962-2007$ & $23^{\circ} 56^{\prime} 29^{\prime \prime}$ & $-106^{\circ} 25^{\prime} 27^{\prime \prime}$ & 158 \\
\hline Siqueros & SIQ & $\mathrm{CP}$ & $1966-2012$ & $23^{\circ} 20^{\prime} 26^{\prime \prime}$ & $-106^{\circ} 14^{\prime} 26^{\prime \prime}$ & 40 \\
\hline San Juan & SJN & $\mathrm{SF}$ & $1990-2012$ & $25^{\circ} 28^{\prime} 59^{\prime \prime}$ & $-107^{\circ} 50^{\prime} 35^{\prime \prime}$ & 118 \\
\hline San Joaquín & SJQN & SF & $1978-2012$ & $25^{\circ} 40^{\prime} 04^{\prime \prime}$ & $-108^{\circ} 01^{\prime} 12^{\prime \prime}$ & 144 \\
\hline Sanalona & SNL & SF & $1962-2012$ & $24^{\circ} 48^{\prime} 00^{\prime \prime}$ & $-107^{\circ} 09^{\prime} 45^{\prime \prime}$ & 104 \\
\hline Surutato & SRT & SM & 1961-2012 & $25^{\circ} 48^{\prime} 29^{\prime \prime}$ & $-107^{\circ} 33^{\prime} 37^{\prime \prime}$ & 1462 \\
\hline Tubares & TBR & SF & $1974-2005$ & $26^{\circ} 56^{\prime} 31^{\prime \prime}$ & $-107^{\circ} 58^{\prime} 40^{\prime \prime}$ & 310 \\
\hline Tamazula & TMZ & $\mathrm{SF}$ & $1959-2012$ & $24^{\circ} 56^{\prime} 10^{\prime \prime}$ & $-106^{\circ} 58^{\prime} 30^{\prime \prime}$ & 344 \\
\hline Topolobampo & ТРВ & $\mathrm{CP}$ & $1963-2008$ & $25^{\circ} 37^{\prime} 46^{\prime \prime}$ & $-109^{\circ} 03^{\prime} 20^{\prime \prime}$ & 5 \\
\hline Urique & URQ & SM & $1962-2008$ & $27^{\circ} 10^{\prime} 00^{\prime \prime}$ & $-107^{\circ} 55^{\prime} 00^{\prime \prime}$ & 801 \\
\hline Vinoramas & VNR & $\mathrm{SF}$ & 2000-2012 & $24^{\circ} 44^{\prime} 54^{\prime \prime}$ & $-107^{\circ} 04^{\prime} 37^{\prime \prime}$ & 146 \\
\hline Vasco Gil & VSGL & SM & $1969-2012$ & $25^{\circ} 07^{\prime} 12^{\prime \prime}$ & $-106^{\circ} 21^{\prime} 45^{\prime \prime}$ & 2445 \\
\hline Zopilote & ZPL & $\mathrm{CP}$ & 1979-2012 & $25^{\circ} 43^{\prime} 50^{\prime \prime}$ & $-108^{\circ} 20^{\prime} 45^{\prime \prime}$ & 37 \\
\hline
\end{tabular}


Table 2. Proposed temperature variables, mode of calculation and abbreviation.

\begin{tabular}{ccc}
\hline Temperature Variable & Calculation & Abbreviation \\
\hline Extreme minimum & Extreme annual minimum record & TMin \\
Mean minimum & Average monthly minimum & TMinAvg \\
Annual mean & Annual monthly average & TAvg \\
Mean maximum & Average monthly maximum & TMaxAvg \\
Extreme maximum & Extreme annual maximum record & TMax \\
Temperature range & Average monthly maximum minus average monthly minimum & TR \\
Minimum temperature variability & Median absolute deviation of minimum monthly records & TMinMAD \\
Mean temperature variability & Median absolute deviation of mean monthly records & TAvgMAD \\
Maximum temperature variability & Median absolute deviation of maximum monthly records & TMaxMAD \\
\hline
\end{tabular}

the extreme and averages, since extreme values can illustrate the recurrence of isolated events. Average minimum and maximum values can reveal in a more consistent way a potential trend by removing the variability of unusual extreme events. The set of data of the different stations is not homogeneous in temporal terms; nevertheless we considered including the largest number of stations even when their span of years was relatively short in order to cover the majority of the territory of the watershed to avoid the exclusion of large spatial areas.

Once conformed, the annual time series was tested with the Mann-Kendall procedure at $P<0.05$, to determine the existence of a trend. This is a non-parametrical procedure that do not require the assumptions of data normality, it is essentially a non-parametric form of monotonic regression analysis, and is very useful in time series like the series proposed for this study, another advantage is low sensitivity to sudden breaks due to inhomogeneous data [32]. We evaluated the magnitude of the resulting slope by applying the $Q$ Sen's slope estimator [33]. These analysis were performed using the template developed by [34]. The spatial behavior of the estimated trends was examined by two analysis: 1) the evaluation of the relationship between the slope values of each proposed temperature variable from each station with its corresponding values of latitude, longitude and altitude through a multiple linear regression analysis; and 2) by applying Moran's $I$ index to the $Q$ slope values of each temperature variable proposed. The $I$ index allows to determine if the distribution of determined points in a spatial context is clustered or random in statistical terms. Likewise, in order to generate a smaller and more meaningful set of main factors that describe the role of the variability of the proposed variables in a general context, we performed a factor analysis using Oblimin rotation to determine the role of the variability of the proposed variables. This method of rotation is an oblique technique that assumes that the analyzed variables are correlated. To explore the behavior of the trends in a regional context, we pooled the data of each station within its particular physiographic region and estimated the annual trends in the same manner to analyze them with the same procedure. Finally, we also evaluated the monthly trends of each station of TMin, TAvg, TMax and TR, this level of analysis may provide a more fine grained measure of detail in the temperature trends behavior throughout the year in each site.

\section{Results and Discussion}

\subsection{Annual Trends}

Despite divergent trends were found for all the proposed variables (Table 3), in a general context, the annual trends here described coincide with the prevailing scenario of increasing temperatures in most of the globe [35] and regionally for northwest Mexico [36]. For TMin, the number of stations with increasing or decreasing trends is virtually the same, however an outstanding difference was found in the number of stations with significant increasing trends that almost doubles the number of significant stations with decreasing trends. The main concentration of increasing trends for TMin occurred from the central to the northern coastal sites of the analyzed watershed (Figure 3(a)). The warming process is more evidently mirrored by the analysis of TMinAvg (Figure 3(b)) and TAvg (Figure 4), where the number of stations with increasing trends almost doubles the number of 


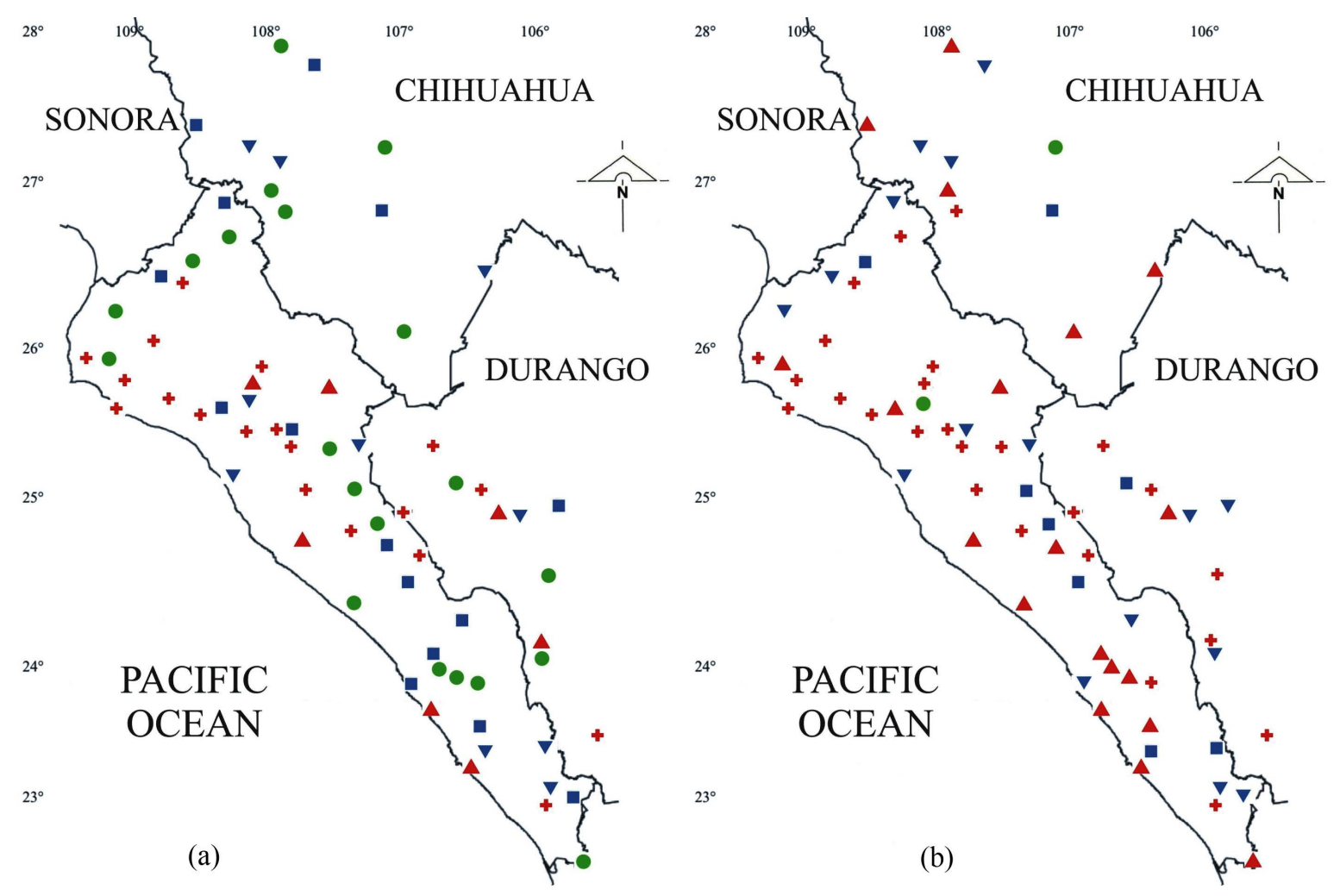

Figure 3. Trends of selected meteorological stations of the North Pacific Watershed in Mexico. Left (a): TMin. Right (b): TMinAvg. Symbology: Red crosses = increasing significant trends, red triangles = increasing non-significant trends, green circles $=$ no detected trend, blue squares $=$ non-significant decreasing trends, blue inverse triangle $=$ significant decreasing trends . See text for abbreviations.

Table 3. Number of stations with decreasing, no detected and increasing $Q$ Sen’s slope trends of the analyzed temperature variables from the selected meteorological stations of the North Pacific Watershed in Mexico. NT = no detected trend. See text for abbreviations.

\begin{tabular}{cccccc}
\hline Variable & Decreasing & Significant Decreasing & NT & Increasing & Significant Increasing \\
\hline TMin & 25 & 10 & 20 & 26 & 18 \\
TMinAvg & 24 & 16 & 2 & 45 & 25 \\
TAvg & 25 & 10 & 0 & 46 & 36 \\
TMaxAvg & 18 & 10 & 2 & 51 & 35 \\
TMax & 20 & 13 & 18 & 33 & 24 \\
TR & 27 & 16 & 1 & 43 & 23 \\
TMinMAD & 13 & 3 & 24 & 34 & 12 \\
TAvgMAD & 26 & 9 & 3 & 42 & 15 \\
TMaxMAD & 19 & 9 & 35 & 19 & 9 \\
\hline
\end{tabular}

sites with decreasing trends; the difference in the number of significant trends is also remarkable, for TAvg, all the statins developed a trend, 46 of them resulted with increasing trends, 36 of these were significant, only 10 stations had significant decreasing trends. The analysis of TMaxAvg reveals that 51 stations had increasing trends, 35 of them significant (Figure 5(a)). TMax shows a marked agglomeration of increasing trends in northwest Sinaloa (Figure 5(b)). The main findings here coincide with the results of [21], who found generalized warming trends in Mexico, but contrastingly, the most relevant rate of change in this case was found for 


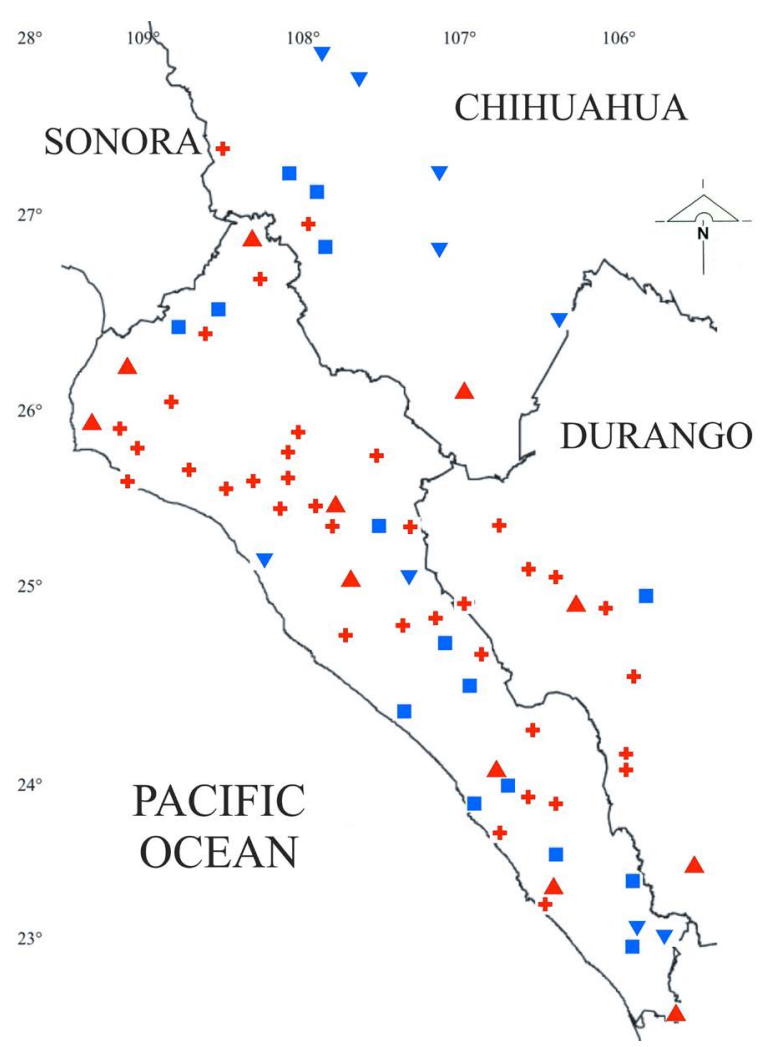

Figure 4. Trends of TAvg of selected meteorological stations of the North Pacific Watershed in Mexico. Symbology as in Figure 3. See text for abbreviations.
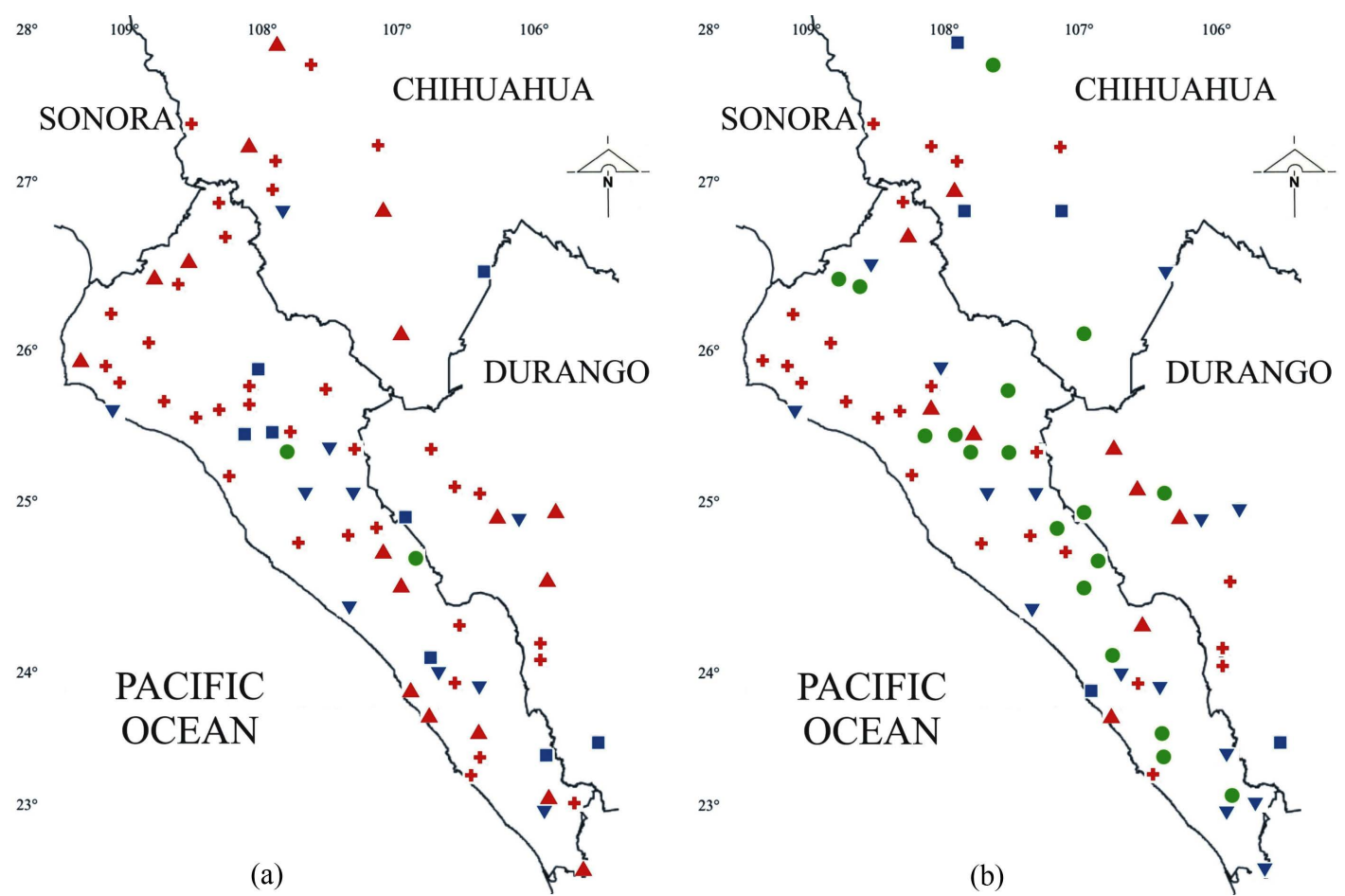

Figure 5. Trends of selected stations of the North Pacific Watershed in Mexico. Left (a): TMaxAvg. Right (b): TMax. Symbology as in Figure 3. See text for abbreviations. 
trends related to minimum temperatures instead of maximum.

The TR analysis results indicate a larger number of stations with increasing tendencies, 23 of the 43 stations were significant, while 16 reported significant decreasing trends. Figure 6 shows that most of the stations with decreasing trends tend to cluster in the middle region of Sinaloa. For this analysis, the results concur with those of [37] and regionally of [23], who also found divergent trends of TR in the nearby state of Zacatecas. The components of TR in this case TMaxAvg-TMinAvg, developed a complex behavior. 20 out of the 27 stations with decreasing trends presented larger TMinAvg slope values, a consistent result with the reports of [14] [38] and [39]. The mechanisms invoked to explain this process include the interaction of cloud cover, soil humidity and rainfall [17]. Also [29] described the effect of urban areas in temperature measurements, in this sense [40] performed an analysis in such areas, describing faster warming trends for minimum temperatures. For this study, some stations that originally were outside urban areas such as ACT, BDG, EDRD, GML, CHX and TPB, were partially surrounded by urban growth. Stations of cities as CLN, GVE, EFRT, ERSR and MCT, were totally engulfed by the urban expansion, hence potentially increasing temperatures in potentially different proportions [41]. The probable effect of this process in adjacent regional extent deserves further research [42]. On the other hand, 43 stations developed increasing TR trends, from these, 26 had larger TMaxAvg slope values, a similar result described by [43] in Spain and for Mexico by [20] [21] [44]. The mechanisms of this process is described by [2] who posed that the conversion of soil cover increase TR due to the decrease of evaporative cooling, consequently increasing TMaxAvg in daytime, when evaporation and maximum temperature occur, a very evident process in semi-arid and seasonal regions. Field evidence of such events is specified by [45] [46].

The measurements of temperature variability show a higher number of stations with increasing trends for

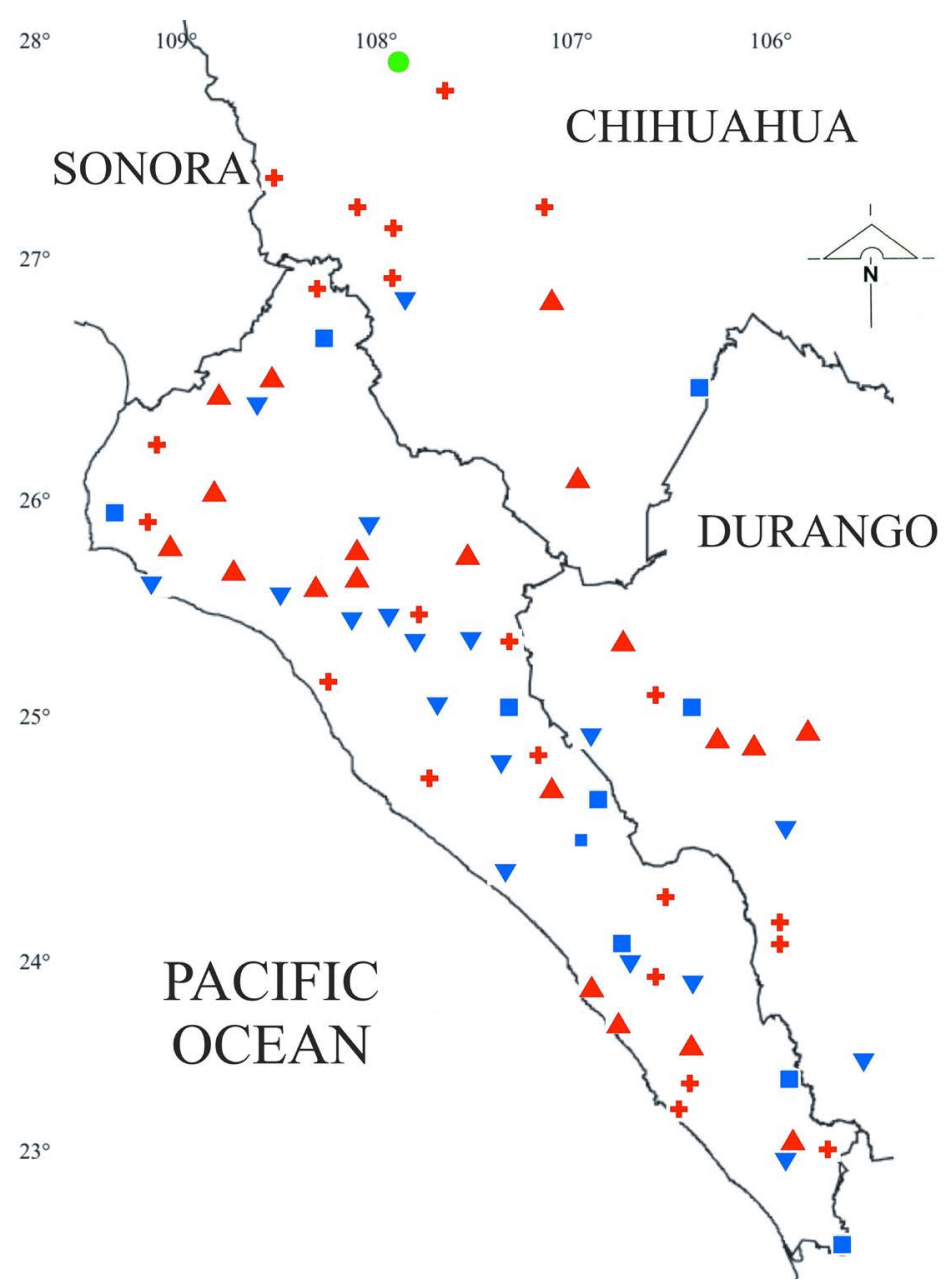

Figure 6. Trends of TR of selected meteorological stations of the North Pacific Watershed in Mexico. Symbology as in Figure 3. See text for abbreviations. 
TMinMAD (Figure 7(a)). Although there are an elevated number of stations without a detected trend, the number of stations with increased variability in TMinMAD is almost three times higher, thirteen stations presented decreasing trends, and only three of these were statistically significant. The occurrence of extreme low records may implicate serious consequences specially if these happen in lowland areas, not only for ecosystem reasons, since most of the vegetation is dominated by tropical elements not enough adapted to below zero temperature events, but also for agriculture activities given the fragility of crops to extreme low records of temperature, a situation that recently occurred in February 2011, when an extended freezing event reached southern coastal sites as LCRZ and EQLT, causing severe losses in almost the entire corn and horticulture crops of the autumn-winter cycle of that year. On the other hand, if extreme high minimum temperatures are recorded, e.g., high records in winter, potential damages in agriculture may also happen, such as the reduction in wheat growth or mango flower formation. This scenario has been discussed in [47].

The TAvgMAD analysis results show a larger number of sites with increasing trends, 15 of the 42 stations with increasing trends were statistically significant, most of them above $24^{\circ} \mathrm{N}$ (Figure $7(\mathrm{~b})$ ). Finally, the TMaxMAD analysis indicates the largest number of stations without detected trends with 33, and an almost equal number of stations with increasing and decreasing trends. DMS, CLN and ECTL are the only sites with increasing trends for TMaxMAD below $24^{\circ} \mathrm{N}$ (Figure 7 (c)). There is a small but noticeable cluster of sites with increasing trends in northwest Sinaloa. These trends may echo extraordinary events of heat waves, and since the summer average maximum temperatures in these sites are already high, even larger maximum events can represent hazardous episodes for cattle and poultry producers, increased use of irrigation water and even alarming conditions for human health. The results found here indicate that a great portion of the sites with warming trends are located within the regions with the most elevated percentages of land cover change, which clearly suggests the large impact of land conversion. In southern coastal areas, the conversion of original land cover is more recent and although the extension of irrigated areas is less conspicuous, it has been steadily increasing; recently 22,500 hectares of land were converted to agriculture with the creation of the Picachos dam in 2006.

A remarkable result was found in the analysis of the previous variables which is the opposite trends of spatially close sites, some of these results can be explained due to the urban heat island effect, such as in EFRT a station now enclosed within an urban space that displays an increasing trend for TAvg and ESBN and EMHN, stations located nearby EFRT but located in the vicinity of river dams and whose trends are negative. Another case would be stations that share relatively homogeneous physical conditions such as SDMD and LTRC in the SM region and display divergent trends for TMinAvg, a potential explanation could be the change in soil cover and its effect on local scales.

\subsection{Spatial Analysis}

Only the $Q$ Sen's slope values of TAvg, TAvgMAD and TMaxMAD (Table 4) associated significantly with the
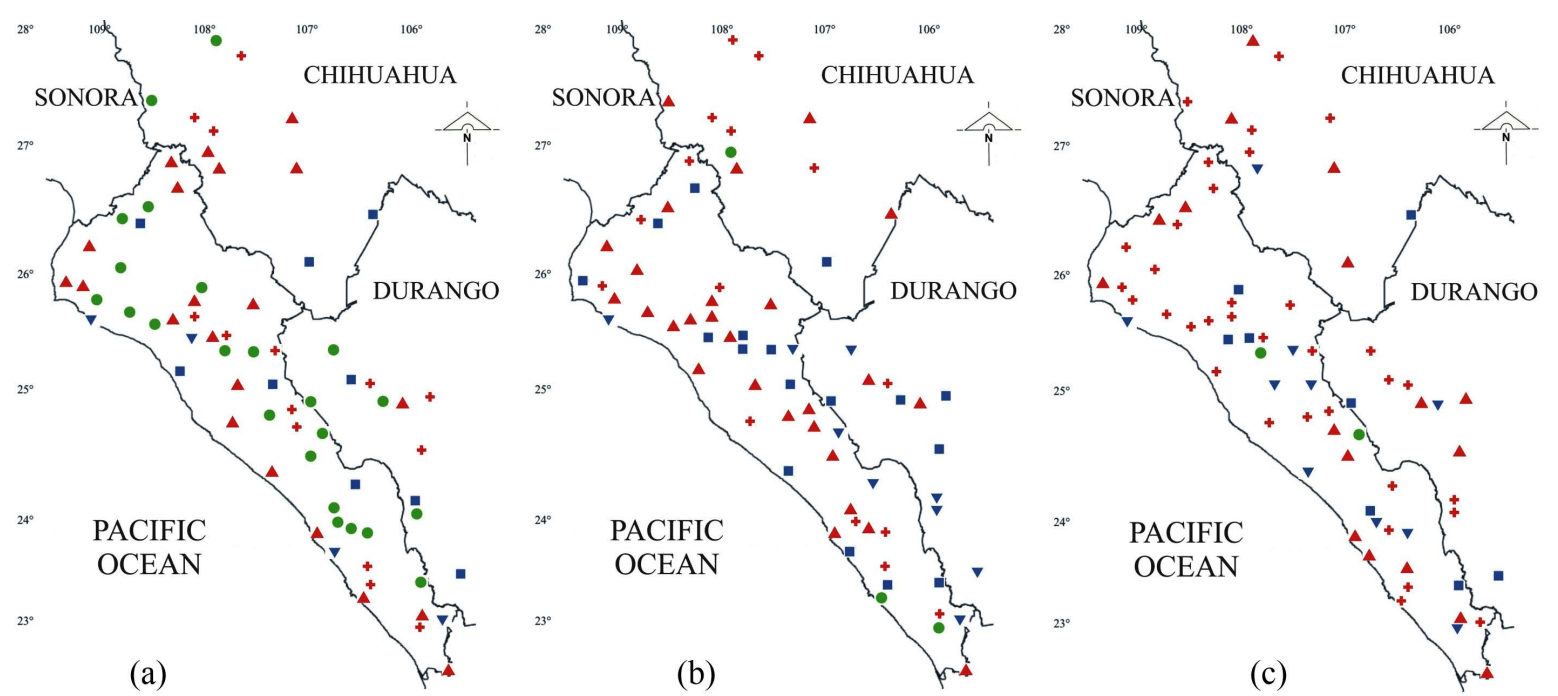

Figure 7. Trends of temperature variability of selected meteorological stations of the North Pacific Watershed in Mexico. Left (a): TMinMAD; Middle (b): TAvgMAD; Right (c): TMaxMAD. Symbology as in Figure 3. See text for abbreviations. 
geographic values of latitude, longitude and altitude. The first two of these factors were the most relevant. An important feature of this analysis is described by the $\beta$-standardized values, for TMin, TMinAvg and TAvg the values of latitude and longitude are negative. This same process is reversed for TMaxAvg, TMinMAD, TAvgMAD and latitude of TMax. Although in a general way altitude was the least important standardized coefficient, its sign also indicates increasing slopes heading towards lower altitudes for TMin, TMinAvg and TAvg and also reversing the process for TMaxAvg, TMax and TR. These results suggests that minimum and averages temperatures and their variability increase at a faster rate heading into the lowlands, whilst the rate of increase of maximum temperatures and their variability is slightly more evident into higher lands and eastern sites. Even when there is a clear role of altitude in temperature behavior, data analysis suggests that latitude is the best predictor of trends slope behavior in relation to their geographical distribution.

The Moran's I index results (Table 5) describes clustered statistically significant results for TMin, TAvg, TAvgMAD and TMaxMAD $Q$ Sen's slopes. The remaining variables also showed positive $I$ values that indicate clustered aggregation, the only exception was found for TMaxAvg which show a negative $I$ value that indicate a potentially dispersed value although not significant in statistical terms.

\subsection{Regional Analysis}

Table 6 shows that the largest mean values of annual temperatures of TMin and TMinAvg occur in the CP region. The mean value of TMin in the SM is negative. The largest values of TAvg, TMax, TMaxAvg and TR are found in the SF.

Even when the magnitude of the averaged $Q$ Sen's slopes for each region is rather small, an initial exploration, indicates that the CP region develop the highest values for TMin, TMinAvg, TAvg and TMaxMAD, this pattern reverses for TMaxAvg, TMax, TR, and TAvgMAD, where the largest slopes values occur in the SM region (Table 7). Cooling average trends were found in the SF region for TMin, TMax, TR and TMaxMAD and in the

Table 4. $\mathrm{r}^{2}$ and $\beta$-standardized coefficients values from multiple regression analysis of latitude, longitude and altitude as independent variables and annual $Q$ Sen's slope trends values from temperature variables as dependent variables. Temperature data is from selected stations of the North Pacific Watershed in Mexico. Bold figures indicate significant values at $P<0.05$. See text for abbreviations.

\begin{tabular}{cccccccccc}
\hline & TMin & TMinAvg & TAvg & TMaxAvg & TMax & TR & TMinMAD & TAvgMAD & TMaxMAD \\
\hline$r^{2}$ & 0.085 & 0.050 & $\mathbf{0 . 2 3 9}$ & 0.075 & 0.092 & 0.066 & 0.060 & $\mathbf{0 . 2 0 6}$ & $\mathbf{0 . 1 2 7}$ \\
Latitude & -0.519 & -0.296 & $-\mathbf{0 . 5 2 5}$ & 0.357 & 0.075 & 0.346 & 0.442 & -0.168 \\
Longitude & -0.634 & -0.370 & -0.462 & 0.094 & -0.241 & 0.204 & 0.309 & 0.153 \\
Altitude & 0.280 & 0.065 & 0.110 & -0.114 & -0.020 & 0.003 & -0.126 & 0.008 \\
\hline
\end{tabular}

Table 5. Moran's $I$ index, $z, P$ and resulting aggregation of spatial correlation analysis of annual $Q$ Sen's slopes trends values from selected meteorological stations from the North Pacific Watershed in Mexico. Bold figures show significant values at $P<$ 0.05 . See text for abbreviation.

\begin{tabular}{ccccc}
\hline Variable & $I$ & $Z$ & $P$ & Aggregation \\
\hline TMin & $\mathbf{0 . 1 4 9 1}$ & 3.0442 & 0.0023 & Clustered \\
TMinAvg & 0.0701 & 1.5543 & 0.1201 & Random \\
TAvg & $\mathbf{0 . 1 1 1 7}$ & 2.3553 & 0.0185 & Clustered \\
TMaxAvg & -0.0351 & -0.3896 & 0.6967 & Random \\
TMax & 0.0465 & 1.1231 & 0.2613 & Random \\
TR & 0.0007 & 0.2732 & 0.7846 & Random \\
TMinMAD & 0.0377 & 0.9671 & 0.3334 & Random \\
TAvgMAD & $\mathbf{0 . 1 1 1 8}$ & 2.3955 & 0.0165 & Clustered \\
TMaxMAD & $\mathbf{0 . 1 1 0 1}$ & 2.3130 & 0.0207 & Clustered \\
\hline
\end{tabular}


Table 6. Averaged values $\left({ }^{\circ} \mathrm{C}\right)$ of temperature variables of physiographic regions of the North Pacific Watershed in Mexico. See text for abbreviations.

\begin{tabular}{ccccccc}
\hline Region & TMin & TMinAvg & TAvg & TMaxAvg & TMax & TR \\
\hline CP & 5.743 & 13.739 & 24.874 & 35.901 & 39.933 & 22.399 \\
SF & 4.282 & 12.602 & 25.170 & 37.680 & 42.076 & 25.461 \\
SM & -3.145 & 4.582 & 17.542 & 30.005 & 35.423 & 25.261 \\
\hline
\end{tabular}

Table 7. Mean values of pooled annual temperature variables $Q$ Sen's slope trends of the physiographic regions of the North Pacific Watershed in Mexico. Bold figures show significant differences between regions based on a Kruskal-Wallis test at $P<$ 0.05. See text for abbreviations.

\begin{tabular}{cccccccccc}
\hline Region & TMin & TMinAvg & TAvg & TMaxAvg & TMax & TR & TMinMAD & TAvgMAD & TMaxMAD \\
\hline CP & 0.0158 & 0.0197 & 0.0165 & 0.0178 & 0.0116 & $\mathbf{0 . 0 0 5 0}$ & 0.0103 & 0.0059 & 0.0025 \\
SF & -0.0064 & 0.0106 & 0.0086 & 0.0137 & 0.0018 & $\mathbf{0 . 0 0 0 6}$ & 0.0074 & 0.0025 & -0.0013 \\
SM & -0.0102 & 0.0020 & -0.0042 & 0.0274 & 0.0146 & $\mathbf{0 . 0 3 5 6}$ & 0.0104 & 0.0089 & -0.0023 \\
Overall & -0.0008 & 0.0106 & 0.0069 & 0.0194 & 0.0090 & $\mathbf{0 . 0 1 3 3}$ & 0.0093 & 0.0056 & -0.0005 \\
\hline
\end{tabular}

SM for TMin, TAvg and TMaxMAD. The differences of annual pooled $Q$ Sen's slope magnitudes between the regions were tested with a non-parametric Kruskal-Wallis procedure since the complete set of data was not normally distributed for five of nine of the proposed variables. TR was the only variable with significant differences. A potential explanation in the increase of minimum temperatures in coastal sites and some sites of the SF is proposed by [48] who proposed that the removal of vegetation could increase the minimum temperatures by increased soil heating. The TR estimated averages are eight times larger for the SM region in reference to the CP, this suggests an exacerbated lengthening of its components, perhaps due to the lack of humidity, which is less notorious in these areas.

In reference to the relation between the magnitudes of the regional $Q$ Sen's slopes averaged trend slopes and the mean averaged temperatures of each area, is clear that the potential effect of change is different between regions. The CP area is evidently more affected by the rate on increase in minimum and average temperatures, in contrast with the SM which show cooling trends in these variables. Contrastingly, the increase in maximum temperatures is more evident in the SM region, but since their annual averages are lower, the impact seems to be less notorious.

\subsection{Principal and Factor Analysis}

Three main factors are retained for a factor analysis, which explain $77.2 \%$ of the total variance (Table 8 ), a Kaiser-Meyer-Olkin analysis is used to determine the data adequacy in order to be factored, based on the correlations among variables, in this case the data is factorable since its values are larger than 0.500: adequacy = 0.663 and Bartlett's sphericity used to determine if sample variances are equal is also significant, $P=0.000$. The highest values of the communalities are obtained for TMax, TR, TMinAvg and TMinMAD, while TMaxAMD recorded the lowest communality value. The loadings of an Oblimin rotation indicate that TMin and TMinAvg are highly correlated to the first component, in the same manner TMax and TMaxAvg have the highest loadings for component 2 and TAvgMAD and TMinMAD for component 3. TAvg associates almost equally with the first two components and negatively with the third.

A two-dimensional scatterplot for the $z$-standardized scores (Figure 8) clusters the sites in relation with the two first main components, principal component 1 (x axis) describes $37.16 \%$ of the total variance principal component 2 (y axis) describes 26.99\%. The graphic describes a clear association of the CP stations with the positive sectors of both components. In contrast, LCRZ and EQLT also coastal stations are located in the negative sectors of both components, suggesting a cooling process. Stations of the SF and the SM regions are scarcely located on positive sectors of both components; this suggests more contrasted trends in these sites or cooling processes. The graphic also describes that sites that are regionally similar behave differently in its asso- 
Table 8. Communality values and oblimin rotated loadings for a factor analysis. Empty cells = loadings $<0.030$.

\begin{tabular}{|c|c|c|c|c|}
\hline & & \multicolumn{3}{|c|}{ Retained Factors Loadings } \\
\hline & & 1 & 2 & 3 \\
\hline Variable & Communality & Minimum & Maximum-Range & MAD \\
\hline TMin & 0.756 & 0.866 & $* * *$ & -0.406 \\
\hline TMinAvg & 0.865 & 0.924 & *** & -0.354 \\
\hline TAvg & 0.707 & 0.460 & 0.415 & -0.718 \\
\hline TMaxAvg & 0.786 & $* * *$ & 0.872 & $* * *$ \\
\hline TMax & 0.888 & $* * *$ & 0.910 & $* * *$ \\
\hline TR & 0.885 & -0.628 & 0.685 & 0.318 \\
\hline TMinMAD & 0.694 & -0.382 & $* * *$ & 0.807 \\
\hline TMAvgMAD & 0.850 & $* * *$ & $* * *$ & 0.913 \\
\hline \multirow[t]{2}{*}{ TMaxMAD } & 0.512 & 0.609 & 0.385 & $* * *$ \\
\hline & \%Variance & 37.157 & 29.990 & 12.972 \\
\hline
\end{tabular}

ciation with the principal components, such as EPLY and GML that are nearby each other. In the other extreme, sites that are very different in terms of region, behave equally, such as VSGL and HZGZ. This result coincides with the multiple regressions and the regional analysis, larger magnitudes of slope trends of minimum and average temperatures are affecting more evidently coastal sites, occurring the opposite in higher and eastern sites.

\subsection{Monthly Analysis}

A first coarse analysis of the monthly trends is based on the number of stations with increasing, no detected and decreasing trends Figure 9(b) shows that TAvg is the variable with the most contrasted results in the ratio increasing/decreasing trends. TMin (Figure 9(a)) shows a similar behavior although less obvious. Both variables develop a similar behavior with an ascending number of stations with increasing trends from January to June, then a sudden decrease in July, probably due to the start of the rainy season and a more elevated number of stations with decreasing trends in December. TMax (Figure 9(c)) is the variable with the most elevated number of stations without a detected trend. December is the month with the highest number of stations with decreasing trends. Finally, TR (Figure 9(d)), describes a contrasted behavior, from January to June the number of decreasing trends is more evident, then the tendency reverses form July to December.

A more fine-grained analysis regarding the physiographic areas and their monthly slope values (Table 9) shows that for TMin the CP area develops in general the largest $Q$ Sen's slope values. Significant differences occurred in January, when the SF and the SM regions displayed negative average trends and in June and November. Another relevant feature is detected in th SM when in January, February and from July to December their averages are negative. For TAvg, none of the monthly differences resulted significant. The behavior detected here reveals that in the first six months the highest slope values were detected in the CP area, this tendency changes from July to September when the highest averages are shared between the CP and the SM regions, in December all the regions developed negative average trends. TMax almost totally reverses the previous trends, with the exception of June, in the remaining months the highest values of the trends occurred in the SM region. TR is the variable with the maximum number with significant monthly differences, from January to May, and November to December, besides, the nature of the sign is also relevant, as in most of the months in the CP region the TR sign trends are negative, in the SM region, all year long the monthly trends are positive. In the SF region the sign of the trends is mixed. Figure 10 describes that for TMin and TAvg (Figure 10(a), and Figure 10(b)) respectively, the monthly averages slope values for SM are smaller, reversing this process for TMax and TR (Figure 10(c), and Figure 10(d)) respectively. 


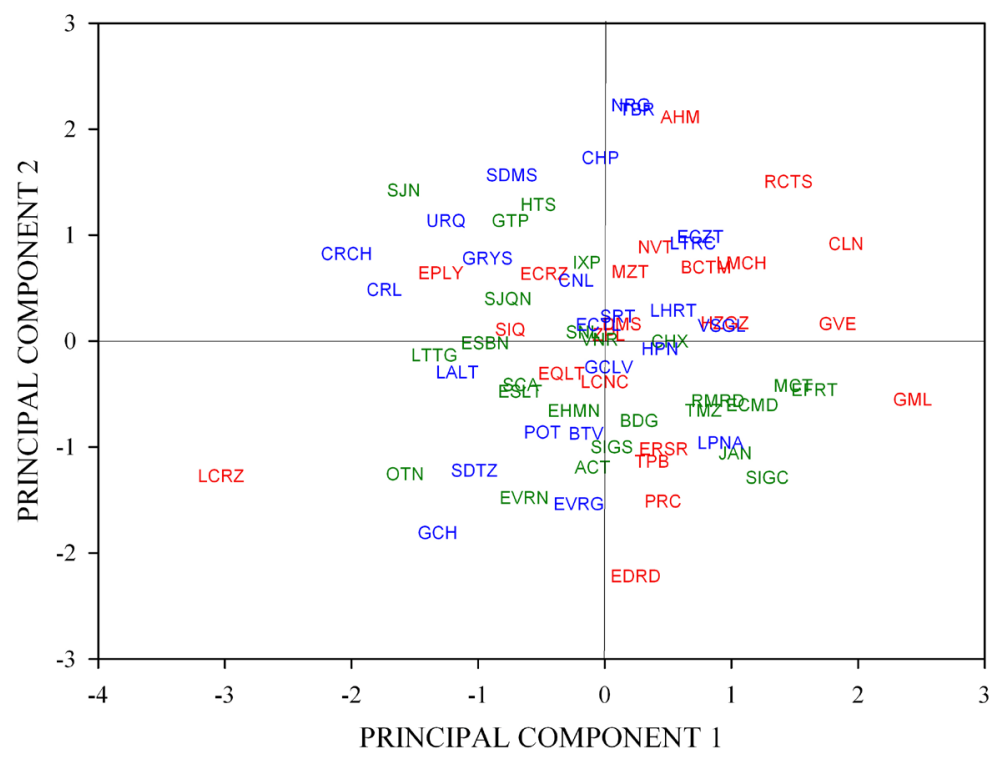

Figure 8. Two dimensional scatterplot of $z$-standardized scores after Oblimin rotation of $Q$ Sen's slope values of temperature variables of selected stations of the North Pacific watershed in Mexico. Red figures = CP stations, green figures $=$ SF stations, blue figures $=$ SM stations. See text for abbreviations.
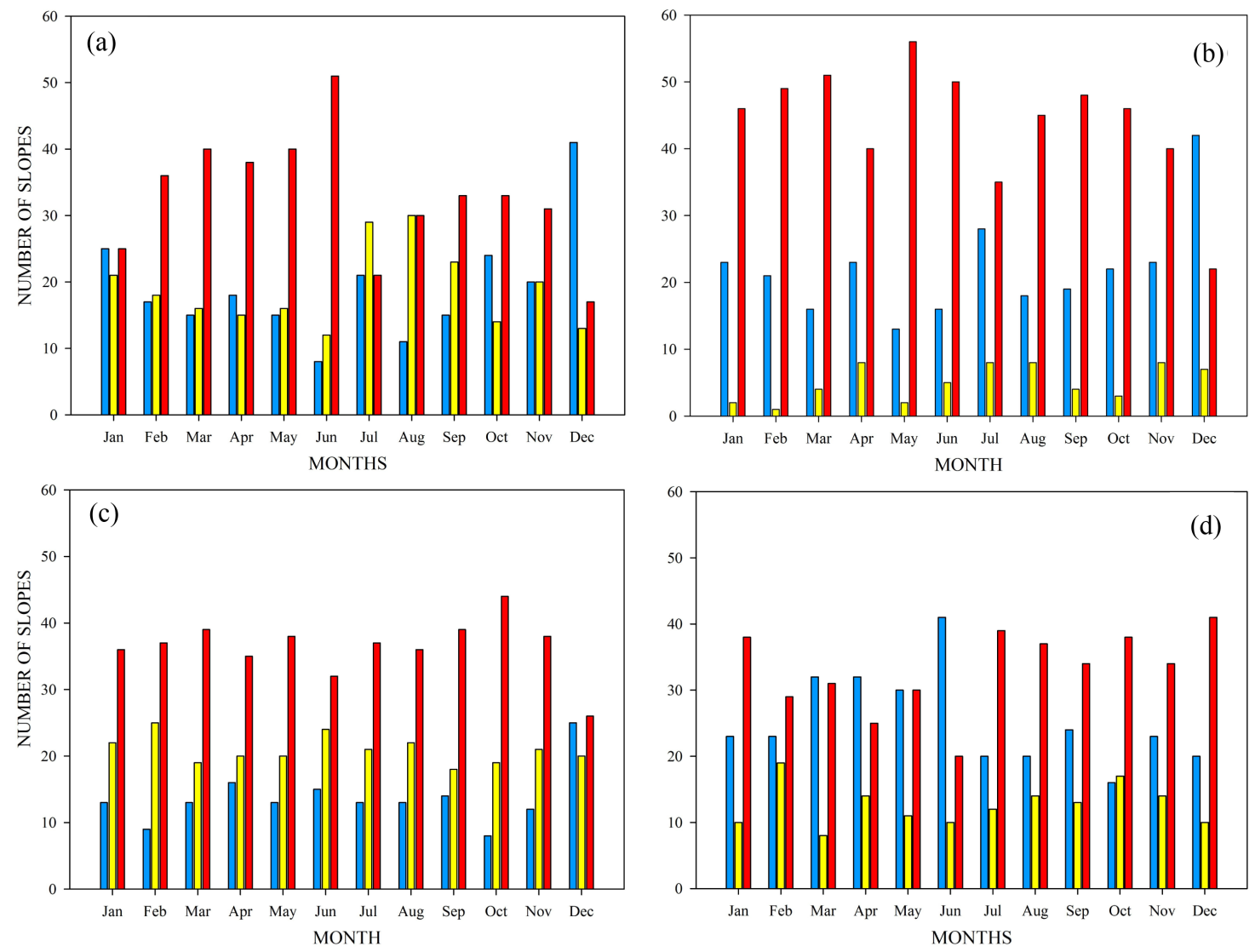

Figure 9. Number of stations with decreasing trends (blue bars), no detected trends (yellow bars) and increasing trends (red bars) of temperature variables for each month of selected stations of the North Pacific Watershed in Mexico. Upper left (a) = TMin. Upper right (b) = TAvg. Lower left (c) = TMax. Lower right (d) = TR. See text for abbreviations. 


\section{Conclusions}

The effect of human activities on climate at different scales of time and space has been subject of intense debate, sometimes under political and economic scrutiny. According to [1], the most conspicuous anthropogenic cause of climate change is the emission of greenhouse gases. In particular within the North Pacific Watershed the amount of emissions is relatively low and not related to industry but to the increasing and uncontrolled amount of automotive engines and the poor management practices in agriculture fields by the massive burning of crops stubble. The evidence described in this analysis suggests that within this watershed and markedly in the CP and SF regions the main cause that contributes to climate change is the conversion of the original vegetation into agriculture fields, and on a minor scale but not least important, the urbanization and hence the urban heat island effect. The mechanisms for these effects have been demonstrated by modeling programs [49]-[51] among many others that have depicted the reduced evapotranspiration as a main cause of warming as a consequence of deforestation in seasonal and arid zones as the one here analyzed. The conversion of natural forest into agricultural fields and its warming effect has been also widely documented by field evidence at different spatial scales [44] [52] [53]. In the North Pacific Watershed, specifically in Sinaloa the transformation of original vegetation into agricultural land has been taking place since the decade of the 20s in the past century, increasing its pace in the mid 50s and early 60s with the construction of river dams and irrigation channels, mainly in the middle and northern regions, where are found $88 \%$ of the total irrigated are in the region, decimating essentially the vegetation of the CP [54]. From the early 70s decade, an intensifying pressure on the SF has also occurred due to the expansion of temporal agriculture which has removed large portions of the vegetation mainly through the slash-and-burn methods, or with the relatively scarce but also increasing artisanal charcoal industry and more recently with the severe land cover destruction due to opencast mining activities. The changes in the SM have
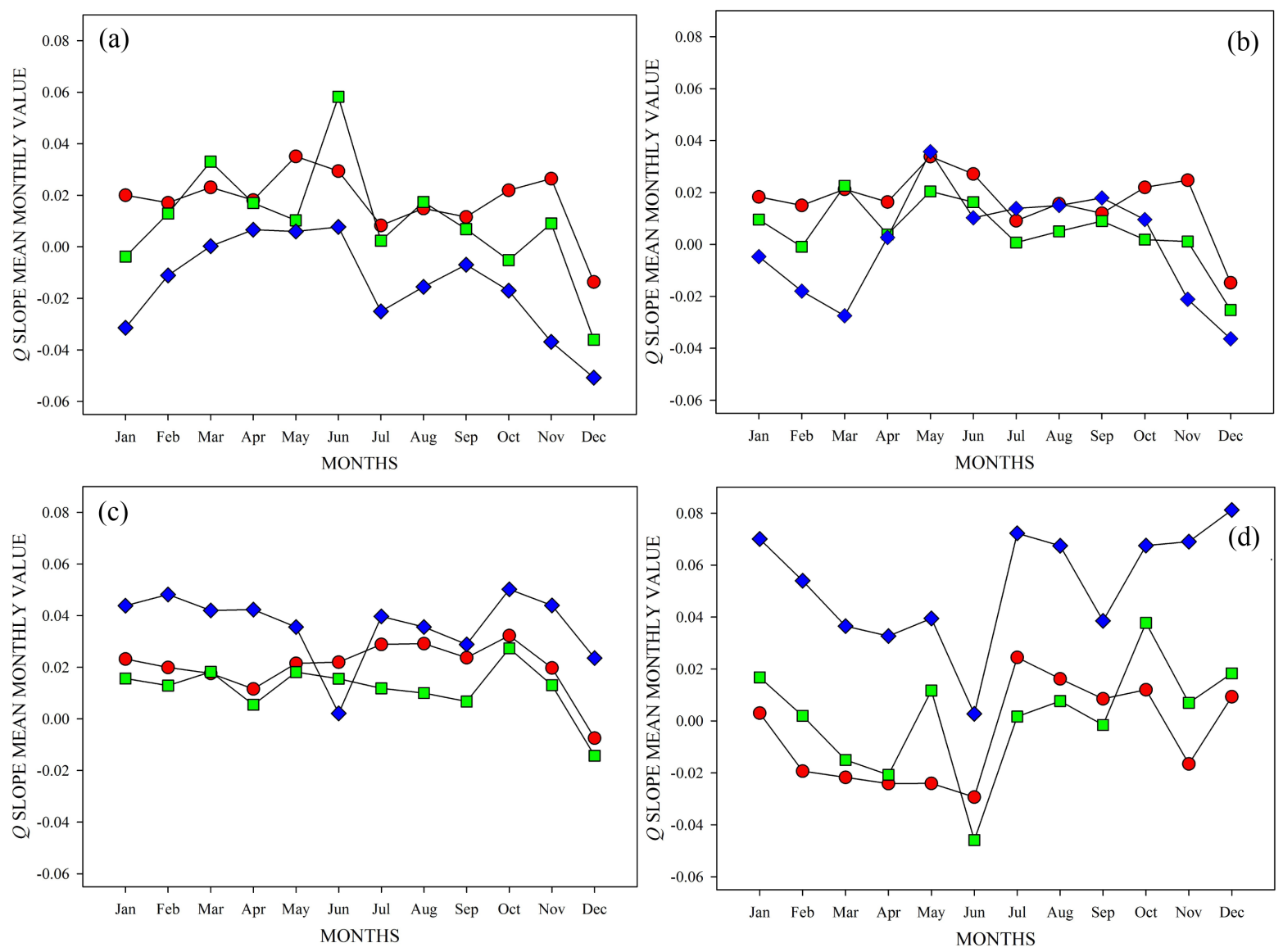

Figure 10. Mean $Q$ Sen's trend slope values of temperature variables from physiographic regions of the North Pacific Watershed in Mexico. Upper left (a) = TMin. Upper right (b) = TAvg. Lower left (c) = TMax. Lower right = TR (d). Symbology: red cicles $=\mathrm{CP}$, green squares $=\mathrm{SF}$ and blue diamonds $=\mathrm{SM}$. See text for abbreviations. 
Table 9. Mean monthly values of $Q$ Sen's slope trends of temperature variables of three physiographic regions of the North Pacific Watershed in Mexico. Bold figures indicate Kruskal-Wallis test significant differences at $P<0.05$. See text for abbreviations.

\begin{tabular}{ccccccccccccccc}
\hline Variable & Region & Jan & Feb & Mar & Apr & May & Jun & Jul & Aug & Sep & Oct & Nov & Dec \\
\hline \multirow{2}{*}{ TMin } & CP & $\mathbf{0 . 0 2 0}$ & 0.017 & 0.023 & 0.018 & 0.035 & $\mathbf{0 . 0 2 9}$ & 0.008 & 0.014 & 0.011 & 0.022 & $\mathbf{0 . 0 2 6}$ & -0.013 \\
& SF & $-\mathbf{0 . 0 0 3}$ & 0.012 & 0.033 & 0.017 & 0.010 & $\mathbf{0 . 0 5 8}$ & 0.002 & 0.017 & 0.007 & -0.005 & $\mathbf{0 . 0 0 9}$ & -0.036 \\
& SM & $-\mathbf{0 . 0 3 1}$ & -0.011 & 0.001 & 0.006 & 0.005 & $\mathbf{0 . 0 0 7}$ & -0.025 & -0.015 & -0.006 & -0.016 & $-\mathbf{0 . 0 3 6}$ & -0.050 \\
& CP & 0.018 & 0.015 & 0.021 & 0.016 & 0.033 & 0.027 & 0.009 & 0.015 & 0.012 & 0.022 & 0.024 & -0.014 \\
\multirow{2}{*}{ TAvg } & SF & 0.009 & -0.001 & 0.022 & 0.003 & 0.020 & 0.016 & 0.001 & 0.005 & 0.009 & 0.002 & 0.001 & -0.025 \\
& SM & -0.004 & -0.018 & -0.027 & 0.002 & 0.035 & 0.010 & 0.014 & 0.015 & 0.018 & 0.009 & -0.021 & -0.036 \\
& CP & 0.023 & 0.019 & 0.017 & 0.011 & 0.021 & 0.022 & 0.028 & 0.029 & 0.024 & 0.032 & 0.019 & -0.007 \\
TMax & SF & 0.016 & 0.013 & 0.018 & 0.005 & 0.018 & 0.016 & 0.012 & 0.010 & 0.007 & 0.027 & 0.013 & -0.014 \\
& SM & 0.043 & 0.048 & 0.042 & 0.042 & 0.035 & 0.002 & 0.039 & 0.035 & 0.028 & 0.050 & 0.044 & 0.023 \\
& CP & $\mathbf{0 . 0 0 3}$ & $-\mathbf{0 . 0 1 9}$ & $\mathbf{- 0 . 0 2 1}$ & $\mathbf{- 0 . 0 2 4}$ & $\mathbf{- 0 . 0 2 4}$ & -0.029 & 0.024 & 0.016 & 0.008 & 0.012 & $-\mathbf{0 . 0 1 6}$ & $\mathbf{0 . 0 0 9}$ \\
& TR & SF & $\mathbf{0 . 0 1 6}$ & $\mathbf{0 . 0 0 2}$ & $\mathbf{- 0 . 0 1 5}$ & $\mathbf{- 0 . 0 2 0}$ & $\mathbf{0 . 0 1 1}$ & -0.045 & 0.001 & 0.007 & -0.001 & 0.037 & $\mathbf{0 . 0 0 6}$ & $\mathbf{0 . 0 1 8}$ \\
& SM & $\mathbf{0 . 0 7 0}$ & $\mathbf{0 . 0 5 3}$ & $\mathbf{0 . 0 3 6}$ & $\mathbf{0 . 0 3 2}$ & $\mathbf{0 . 0 3 9}$ & 0.002 & 0.072 & 0.067 & 0.038 & 0.067 & $\mathbf{0 . 0 6 9}$ & $\mathbf{0 . 0 8 1}$
\end{tabular}

been less severe, but also increasing and not the least important. Chihuahua and Sinaloa have a net loss of 13,602 and 8592 hectares of forest respectively. In Durango, the situation is reverted with an increase in forested areas of 1469 hectares per year [55].

The biological responses due to climate change have been extensively documented [56] [57], particularly for plants, from physiological function [58]-[60], to distribution changes [61]-[63] and ultimately to adaptive responses [64] [65]. For Mexico, [66] described the potential changes in vegetation in a drier and warmer scenario. For the analyzed region, the potential changes include the reduction of pine and oak-pine forest areas, the upward migration of tropical dry forest and thorn forest, the nearly extinction of cloud forest and an even worse pressure on the already decimated riverine vegetation. The interaction between climate and biotic factors is a crucial element in the ecosystems functioning, since its relationship produces feedbacks that drive a great portion of its stability [67]. Given the current scenario in most of the watershed, if counter measures are not taken, the level of environmental degradation due to anthropogenic activities that are involved in the mechanisms of climate change, will only increase the negative feedback spiral, not only affecting the biological and economic productive responses, but also creating conditions for economic and social unrest.

\section{Acknowledgements}

We want to thank the helpful assistance of Carlos Alberto Rendón and Artemisa García Garnica at the Comisión Nacional del Agua for kindly providing the climate data.

\section{Financial Support}

This study was supported by the Programa Integral de Fortalecimiento Institucional (PIFI2013) and the Programa de Fomento y Apoyo a la Investigación de la Universidad Autónoma de Sinaloa (PROFAPI-UAS, 2013/ 189).

\section{References}

[1] Solomon, S., Qin, D., Manning, M., Chen, Z., Marquis, M., Averyt, K.B., Tignor, M. and Miller, H.L. (2007) Climate Change 2007: The Physical Science Basis. Contribution of Working Group I to the Fourth Assessment of the Intergovernmental Panel on Climate Change. Cambridge University Press, Cambridge.

[2] Defries, R.S., Bounoua, L. and Karl, T.R. (2002) Human Modification of the Landscape and Surface Climate in the Next Fifty Years. Global Change Biology, 8, 438-458.

[3] Sitch, S., Brovkin, V., Bloh, W., van Vuuren, D., Eickhout, B. and Ganopolski, A. (2005) Impacts of Future Land Co- 
ver Changes on Atmospheric $\mathrm{CO}_{2}$ and Climate. Global Biogeochemical Cycles, Published Online. http://dx.doi.org/10.1029/2004GB002311

[4] Balling, R.C. (1988) The Climatic Impacts of a Sonoran Vegetation Discontinuity. Climatic Change, 13, 99-109. http://dx.doi.org/10.1007/BF00140163

[5] Campra, P., García, M., Canton, Y. and Palacios-Orueta, A. (2008) Surface Temperature Cooling Trends and Negative Radiative Forcing Due to Land Use Change toward Greenhouse Farming in Southeastern Spain. Journal of Geophysical Research: Atmospheres, 113, Published Online.

[6] Núñez, M.N., Ciapessoni, H.H., Rolla, A., Kalnay, E. and Cai, M. (2008) Impact of Land Use and Precipitation Changes on Surface Temperature Trends in Argentina. Journal of Geophysical Research: Atmospheres, 113, Published Online. http://dx.doi.org/10.1029/2007JD008638

[7] Hu, Y., Dong, W. and He, Y. (2010) Impact of Land Surface Forcings on Mean and Extreme Temperature in Eastern China. Journal of Geophysical Research: Atmospheres, 115, Published Online.

[8] Wu, Z., Zhang, H., Krause, C.M. and Cobb, N.S. (2010) Climate Change and Human Activities: A Case Study in Xinjiang, China. Climate Change, 99, 457-472. http://dx.doi.org/10.1007/s10584-009-9760-6

[9] Stohlgren, T.J., Chase, T.N., Pielke, R.A., Kittel, T.G. and Baron, J.S. (1998) Evidence That Local Land Use Practices Influence Regional Climate, Vegetation and Stream Flow Patterns in Adjacent Natural Areas. Global Change Biology, 4, 495-504.

[10] Bonfills, C. and Lobell, D. (2007) Empirical Evidence for a Recent Slowdown in Irrigation-Induced Cooling. Proceedings of the National Academy of Sciences of the United States of America, 104, 13582-13587. http://dx.doi.org/10.1073/pnas.96.17.9701

[11] Wendler, G., Chen, L. and Moore, B. (2012) The First Decade of the New Century: A Cooling Trends for Most of Alaska. The Open Atmospheric Science Journal, 6, 111-116.

[12] Mahmood, R., Pielke, R.A., Hubbard, K.G., Niyogi, D., Dirmeyer, P.A., McAlpine, C., Carleton, A.M., Hale, R., Gameda, S., Beltrán-Przekurat, A., Baker, B., McNider, R., Legates, D.R., Sheperd, M., Du, J., Blanken, P.D., Frauenfeld, O.W., Nair, U.S. and Fall, S. (2014) Land Cover Changes and Their Biogeophysical Effects on Climate. International Journal of Climatology, 34, 929-953. http://dx.doi.org/10.1002/joc.3736

[13] Warren, R., Price, J., Fischlin, A., Santos, S.N. and Midgley, G. (2014) Increasing Impacts of Climate Change upon Ecosystems with Increasing Global Mean Temperature Rise. Climatic Change, 106, 141-177. http://dx.doi.org/10.1007/s10584-010-9923-5

[14] Easterling, D.R., Horton, B., Jones, P.D., Peterson, T.C., Karl, T.R., Parker, D.E., Salinger, M.J., Razuvayev, V., Plummer, N., Jamason, P. and Folland, C.K. (1997) Maximum and Minimum Temperature Trends for the Globe. Science, 277, 364-366. http://dx.doi.org/10.1126/science.277.5324.364

[15] Panda, D.K., Mishra, A., Kumar, A., Mandal, K.G., Thakur, A.K. and Srivastava, R.C. (2014) Spatiotemporal Patterns in the Mean and Extreme Temperatures of India, 1971-2005. International Journal of Climatology, Early View. http://dx.doi.org/10.1002/joc.3931

[16] Meehl, G.A., Tebaldi, C., Walton, G., Easterling, D. and McDaniel, L. (2009) Relative Increase of Record Maximum Temperatures Compared to Record Low Minimum Temperatures in the US. Geophysical Research Letters, 36, Published Online. http://dx.doi.org/10.1029/2009GL040736

[17] Dai, A., Trenberth, K.E. and Karl, T.R. (1999) Effects of Clouds, Soil Moisture, Precipitation and Water Vapor on Diurnal Temperature Range. Journal of Climate, 12, 2451-2473.

[18] Bonan, G.B. (2001) Observational Evidence for Reduction of Daily Maximum Temperature by Croplands in the Midwest United States. Journal of Climate, 14, 2430-2422.

[19] Englehart, P.J. and Douglas, A.V. (2004) Characterizing Regional-Scale Variations in Monthly and Seasonal Surface Air Temperatures over Mexico. International Journal of Climatology, 24, 1897-1909. http://dx.doi.org/10.1002/joc.1117

[20] Englehart, P.J. and Douglas, A.V. (2005) Changing Behavior in the Diurnal Range of Surface Air Temperatures over Mexico. Geophysical Research Letters, 32, Published Online. http://dx.doi.org/10.1029/2004GL021139

[21] Pavia, E.G., Graef, F. and Reyes, J. (2009) Annual and Seasonal Surface Air Temperature Trends in Mexico. International Journal of Climatology, 29, 1324-1329. http://dx.doi.org/10.1002/joc.1787

[22] Weiss, J.L. and Overpeck, J.T. (2005) Is the Sonoran Desert Loosing Its Cool? Global Change Biology, 11, $2065-2077$.

[23] Brito-Castillo, L., Díaz-Castro, S.C. and Ulloa-Herrera, R.S. (2009) Observed Tendencies in Maximum and Minimum Temperatures in Zacatecas, Mexico and Possible Causes. International Journal of Climatology, 29, 211-221. http://dx.doi.org/10.1002/joc.1733

[24] Woodward, F.I. and Williams, B.G. (1987) Climate and Plant Distribution at Local and Global Scales. Vegetatio, 69, 
189-197. http://dx.doi.org/10.1007/BF00038700

[25] Pausas, J.G. and Austin, M.P.K. (2001) Patterns of Plants Species Richness in Relation to Different Environments: An Appraisal. Journal of Vegetation Science, 12, 153-166. http://dx.doi.org/10.2307/3236601

[26] Criddle, R.S.D., Smith, B.N. and Hansen, L.D. (1997) A Respiration Based Description of Plant Growth Rate Responses to Temperature. Planta, 201, 441-445. http://dx.doi.org/10.1007/s004250050087

[27] Bowers, J.E. (1981) Catastrophic Freezes in the Sonoran Desert. Desert Plants, 2, 232-236.

[28] Larcher, W. (2001) Physiological Plant Ecology. Ecophysiology and Stress Physiology of Functional Groups. 4th Edition, Springer Verlag, Berlin.

[29] Rzedowski, J. (2006) Vegetación de México. 1era edición digital, Comisión Nacional para Conocimiento y Uso de la Biodiversidad, México City.

[30] Comisión Nacional del Agua (2010) Manual Teórico Práctico del Observador Meteorológico de Superficie. Secretaría de Medio Ambiente y Recursos Naturales, México City.

[31] Karl, T.R., Diaz, H.F. and Kukla, G. (1988) Urbanization: Its Detection and Effect in the United States Climate Record. Journal of Climate, 1, 1099-1123. http://dx.doi.org/10.1175/1520-0442(1988)001<1099:UIDAE1>2.0CO;2

[32] Helsel, D.R. and Hirsch, R.M. (2002) Statistical Methods in Water Resources. United States Geological Survey.

[33] Sen, P.K. (1968) Estimates of the Regression Coefficient Based on Kendall's Tau. Journal of the American Statistical Association, 63, 1379-1389. http://dx.doi.org/10.1080/01621459.1968.10480934

[34] Salmi, T., Maata, A., Antilla, P., Ruoho-Airola, T. and Amnell, T. (2002) Detecting Trends of Anual Values of Atmospheric Pollutants by the Mann-Kendall Test and Sen’s Slope Estimates-The Excel Template Application Makesens. Finnish Meteorological Institute, Helsinki.

[35] Kennedy, J.J., Morice, C.P., Parker, D.E. and Tichner, H.A. (2013) Global and Regional Climate in 2012. Weather, 68, 240-246. http://dx.doi.org/10.1002/wea.2157

[36] Gutiérrez-Ruacho, O.G., Brito-Castilo, L., Diaz-Castro, S.C. and Watts, C.J. (2010) Trends in Rainfall and Extreme Temperatures in Northwestern Mexico. Climate Research, 42, 133-142. http://dx.doi.org/10.3354/cr00874

[37] Türkeș, T.M. and Sümer, U.M. (2004) Spatial and Temporal Patterns of Trends and Variability in Diurnal Temperature Ranges of Turkey. Theoretical and Applied Climatology, 77, 195-227. http://dx.doi.org/10.1007/s00704-003-0024-5

[38] Karl, T.R., Jones, P.D., Knight, R.W., Kukla, G., Plummer, N., Razuvayev, V., Gallo, K.P., Lindsay, J., Charlson, R. and Peterson, T.C. (1993) A New Perspective on Recent Global Warming: Asymmetric Trend of Daily Maximum and Minimum Temperature. Bulletin of the American Meteorological Society, 74, 1007-1023.

[39] Vose, R.S., Easterling, D.R. and Gleason, B. (2004) Maximum and Minimum Temperature Trends for the Globe: An Update through 2004. Geophysical Research Letters, 32, Published Online. http://dx.doi.org/10.1029/2005GL024379

[40] Englehart, P.J. and Douglas, A.V. (2003) Urbanization and Seasonal Temperature Trends: Observational Evidence from a Data-Sparse Part of North America. International Journal of Climatology, 24, 1253-1263. http://dx.doi.org/10.1002/joc.935

[41] Ren, G., Zhou, Y., Chu, Z., Zhou, J., Zhang, A., Guo, J. and Liu, X. (2008) Urbanization Effects on Observed Surface Air Temperature Trends in North China. Journal of Climate, 21, 1333-1348.

[42] Jones, P.D., Lister, D.H. and Li, Q. (2008) Urbanization Effects in Large-Scale Temperature Records, with an Emphasis on China. Journal of Geophysical Research: Atmospheres, 113, Published Online. http://dx.doi.org/10.1029/2008JD009916

[43] del Río, S., Fraile, R., Herrero, L. and Peñas, A. (2007) Analysis of Recent Trends in Mean Maximum and Minimum Temperatures in a Region of the NW of Spain (Castilla y León). Theoretical and Applied Climatology, 90, 1-12. http://dx.doi.org/10.1007/s00704-006-0278-9

[44] Peralta-Hernández, A.R., Balling Jr., R.C. and Barba-Martínez, L.R. (2009) Analysis of Near-Surface Diurnal Temperature Variations and Trends in Southern Mexico. International Journal of Climatology, 29, 205-209. http://dx.doi.org/10.1002/joc.1715

[45] Balling Jr., R.C., Klopatek, J.M., Hildebrandt, M.L., Moritz, C.K. and Watts, C.J. (1998) Impacts of Land Degradation on Historical Temperature Records from the Sonoran Desert. Climate Change, 40, 669-681. http://dx.doi.org/10.1023/A:1005370115396

[46] Bounoua, L., DeFries, R.S., Collatz, G.J., Sellers, P. and Khan, H. (2002) Effects of Land cover Conversion on Surface Climate. Climate Change, 52, 29-64. http://dx.doi.org/10.1023/A:1013051420309

[47] Rahmstorf, S. and Coumou, D. (2011) Increase of Extreme Events in a Warming World. Proceedings of the National Academy of Sciences of the United States of America, 108, 17905-17909.

[48] Zhou, L., Dickinson, R.E., Tian, Y., Vose, R.S. and Dai, Y. (2007) Impact of Vegetation Removal and Soil Aridation 
on Diurnal Temperature Range in a Semiarid Region: Application to the Sahel. Proceedings of the National Academy of Sciences, 104, 17937-17942. http://dx.doi.org/10.1073/pnas.0700290104

[49] Salati, E. and Nobre, C.A. (1991) Possible Climatic Impacts of Tropical Deforestation. Climatic Change, 19, $177-196$.

[50] Feddema, J.J., Oleson, K.W., Bonan, G.B. Mearns, L.O., Buja, L.E., Meehl, G.A. and Washington, W.M. (2005) The Importance of Land-Cover Change in Simulating Future Climates. Science, 310, 1674-1678.

[51] Davin, E.L. and Noblet-Decoudré, N. (2010) Climatic Impact of Global-Scale Deforestation: Radiative versus Non-Radiative Processes. Journal of Climate, 23, 97-112. http://dx.doi.org/10.1175/2009JCLI3102.1

[52] Costa, M.H., Yanagi, S.N.M., Souza, P.J.O.P., Ribeiro, A. and Rocha, E.J.P. (2007) Climate Change in the Amazonia Caused by Soybean Cropland Expansion, as Compared to Caused by Pasture Land Expansion. Geophysical Research Letters, 34, Published Online. http://dx.doi.org/10.1029/2007GL029271

[53] Snyder, P.K. (2010) The Influence of Tropical Deforestation on the Northern Hemisphere by Atmospheric Teleconnections. Earth Interactions, 14, 1-34.

[54] EADR. Estadísticas Agrícolas de los Distritos de Riego, Año Agrícola 2009-2009, SEMARNAT 2010.

[55] Céspedes-Flores, S.E. and Moreno-Sánchez, E. (2010) Estimación de la pérdida del recurso forestal y su relación con la reforestación en las entidades federativas de México. Investigación Ambiental, 2, 5-13.

[56] Parmesan, C. and Yohe, G. (2003) A Globally Coherent Fingerprint of Climate Change Impacts across Natural Systems. Nature, 421, 37-42. http://dx.doi.org/10.1038/nature01286

[57] Parmesan, C. (2006) Ecological and Evolutionary Responses to Recent Climate Change. Annual Review of Ecology, Evolution and Systematics, 37, 637-669.

[58] Bradley, N.L., Leopold, A.C., Ross, J. and Huffaker, W. (1999) Phenological Changes Reflect Climate Change in Wisconsin. Proceedings of the National Academy of Sciences of the United States of America, 96, 9701-9704.

[59] Rennenberg, H., Loreto, F., Polle, A., Brilli, F., Fares, S., Beniwal, R.S. and Gessler, A. (2006) Physiological Responses of Forests Trees to Heat and Drought. Plant Biology, 8, 556-571. http://dx.doi.org/10.1055/s-2006-924084

[60] Sherry, R.A., Zhou, X., Gu, S., Arnone, J.A., Schimel, D.S., Verburg, P.S., Wallace, L.L. and Luo, Y. (2007) Divergence of Reproductive Phenology under Climate Warming. Proceedings of the National Academy of Sciences of the United States of America, 104, 198-202. http://dx.doi.org/10.1073/pnas.0605642104

[61] Pitelka, L.F., Gardner, R.H., Ash, J., Berry, S., Gitay, H., Noble, I.R. and Saunders, A. (1997) Plant Migration under Climate Change. American Scientist, 85, 464-473.

[62] Sánz-Elorza, M., Dana, E.D., González, A. and Sobrino, E. (2003) Changes in the High-Mountain Vegetation of the Central Iberian Peninsula as a Probable Sign of Global Warming. Annals of Botany, 92, 273-280. http://dx.doi.org/10.1093/aob/mcg130

[63] Kelly, A.E. and Goulden, M.L. (2008) Rapid Shifts in Plant Distribution with Recent Climate Change. Proceedings of the National Academy of Sciences of the United States of America, 105, 11823-11826. http://dx.doi.org/10.1073/pnas.0802891105

[64] Bradshaw, W.E. and Holzapfel, C.M. (2001) Genetic Shift in Photoperiodic Response Correlated with Global Warming. Proceedings of the National Academy of Sciences of the United States of America, 98, 14509-14511. http://dx.doi.org/10.1073/pnas.241391498

[65] van Dijk, H. and Hautekèete, N. (2007) Long Day Plants and the Response to Global Warming: Rapid Evolution Change in Day Length Sensitivity Is Possible in Wild Beet. Journal of Evolutionary Biology, 20, 349-357. http://dx.doi.org/10.1111/j.1420-9101.2006.01192.x

[66] Villers-Ruiz, I. and Trejo-Vázquez, I. (1997) Assessment of the Vulnerability of Forest Ecosystems to Climate Change in Mexico. Climate Research, 9, 87-93. http://dx.doi.org/10.3354/cr009087

[67] Chapin III, F.S. (2003) Effects of Plant Traits on Ecosystem and Regional Processes: A Conceptual Framework for Predicting the Consequences of Global Change. Annals of Botany, 91, 455-463. 
Scientific Research Publishing (SCIRP) is one of the largest Open Access journal publishers. It is currently publishing more than 200 open access, online, peer-reviewed journals covering a wide range of academic disciplines. SCIRP serves the worldwide academic communities and contributes to the progress and application of science with its publication.

Other selected journals from SCIRP are listed as below. Submit your manuscript to us via either submit@scirp.org or Online Submission Portal.
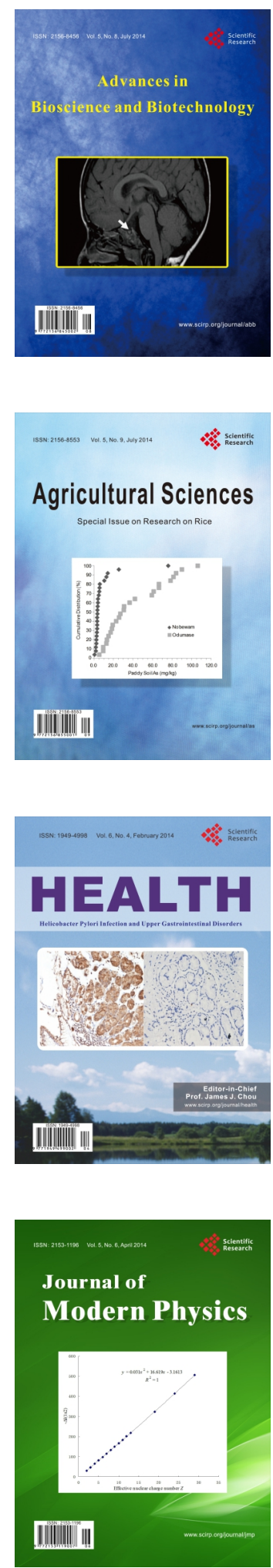
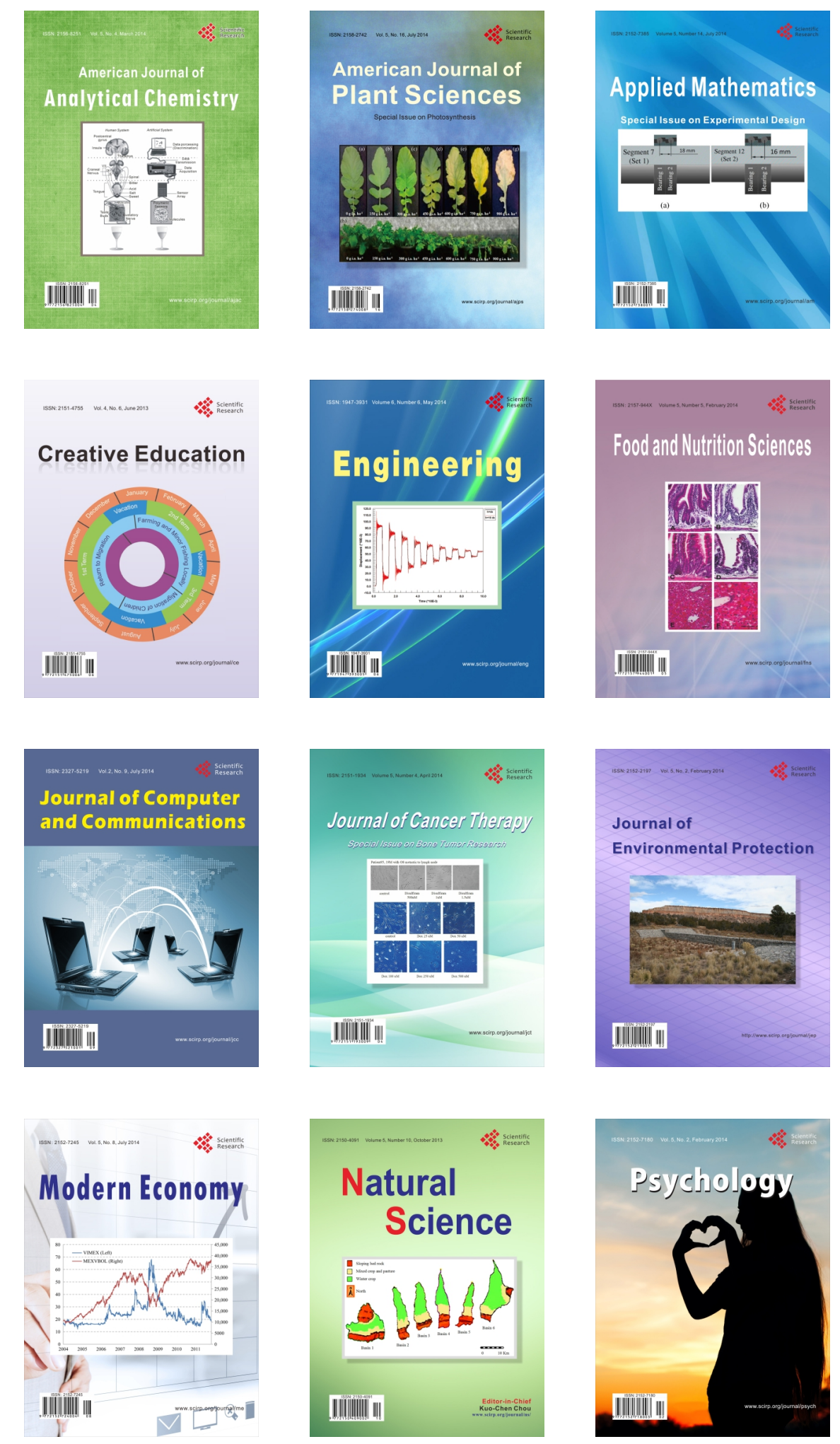